\title{
Granitos peraluminosos intrusivos no Complexo Metamórfico Brusque: registro do magmatismo relacionado a colisão neoproterozóica no Terreno Tijucas, Itapema (SC)
}

\author{
Ruy Paulo Philipp ${ }^{1}$ \& Roberto Sacks de Campos ${ }^{2}$
}

\begin{abstract}
Resumo O Complexo Metamórfico Brusque (CMB) é uma das principais unidades do Terreno Tijucas em Santa Catarina. Na região de Itapema este complexo é composto por uma associação de xistos pelíticos, quartzitos, mármores e rochas calci-silicáticas, com ocorrência subordinada de rochas metavulcânicas máficas, ultramáficas e granitos peraluminosos. Estas unidades estão intercaladas tectonicamente e dispostas segundo uma foliação de baixo ângulo orientada segundo a direção nordeste. Os granitos constituem corpos tabulares de espessuras centimétricas a métricas e mostram relações concordantes com a foliação $\mathrm{S}_{2}$, posicionando-se ao longo das superfícies axiais de dobras isoclinais e apertadas da fase $\mathrm{F}_{2}$. Possuem composição monzogranítica com mineralogia composta por K-feldspato, plagioclásio e quartzo, teores subordinados de muscovita e turmalina, com biotita, granada, monazita, zircão, apatita e minerais opacos como acessórios. A estrutura principal é um bandamento magmático de espessura centimétrica, alternando níveis regulares e contínuos com textura equigranular média a grossa e porções pegmatíticas. $\mathrm{O}$ bandamento é originado pelo preenchimento sucessivo de fraturas por injeções graníticas. Estudos geoquímicos caracterizaram os granitos como representantes do magmatismo peraluminoso relacionado à série cálcico-alcalina alto-K. Os padrões de elementos maiores e traços como razões $\mathrm{La}_{\mathrm{N}} / \mathrm{Yb}_{\mathrm{N}}$ (variando entre 1,34 e 4,66), $\mathrm{K}_{2} \mathrm{O} / \mathrm{Na}_{2} \mathrm{O}$ (entre 0,86 e 1,72), $\mathrm{CaO} / \mathrm{Na}_{2} \mathrm{O}$ (entre 0,11 e 0,44 ) e os baixos teores de $\mathrm{Rb}, \mathrm{Sr}, \mathrm{Zr}$ e de ETR são muito similares aos de granitos peraluminosos descritos em outros cinturões orogênicos. Composições deste tipo são usualmente atribuídas à rochas formadas por fusão parcial de seqüências crustais de composição pelítica deixando um resíduo sólido granulítico. As relações estruturais entre o posicionamento dos corpos graníticos e a evolução metamórfico-deformacional do CMB, associada aos parâmetros geoquímicos e as feições tectônicas e geocronológicas são consistentes com um magmatismo relacionado à fusão crustal em ambiente colisional no final do Ciclo Brasiliano.
\end{abstract}

Palavras-chave: Escudo Catarinense, Terreno Tijucas, Complexo Metamórfico Brusque, Itapema, granitos peraluminosos, geoquímica.

\begin{abstract}
Intrusive peraluminous granites on Brusque Metamorphic Complex: register of Neoproterozoic collisional magmatism in the Tijucas Terrane, Itapema, SC, Brazil. Brusque Metamorphic Complex is one of the main units of the Tijucas terrane in Santa Catarina state. This complex, located in the Itapema region is constituted by metasedimentary association with subordinate presence of mafic and ultramafic metavolcanic rocks and peraluminous granites. The granites have tabular form from centimetric to metric thickness intruding metapelites, mafic and calc-silicate schists. These units are tectonically interposed and disposed to a low angle foliation from northeast-southwest direction. The granites are concordant with the $\mathrm{S}_{2}$ foliation and lie in according to axial surfaces of isoclinal $\mathrm{F}_{2}$ folds. The granite have a monzogranite composition with a K-feldspar, plagioclase and quartz, subordinates quantities of muscovite and tourmaline, with biotite, garnet, monazite, zircon, apatite and opaque minerals as accessories. The main structure is a magmatic banding of centimetric thickness alternating regular and continual levels from medium to coarse equigranular texture as well as pegmatitic texture levels. The banding is originated by successive fulfilling of fractures by granite injections. Geochemical studies characterize the granites as peraluminous magmatism related to high$\mathrm{K}$ calc-alkaline series. The majors and traces elements patterns present values for the ratios $\operatorname{La}_{\mathrm{N}} / \mathrm{Yb}_{\mathrm{N}}(1.34$ to 4.66), $\mathrm{K}_{2} \mathrm{O} / \mathrm{Na}_{2} \mathrm{O}$ (0.86 to 1.72$), \mathrm{CaO} / \mathrm{Na}_{2} \mathrm{O}(0.11$ to 0.44$)$ and low values of $\mathrm{Rb}, \mathrm{Sr}, \mathrm{Zr}$ and $\mathrm{RRE}$, are similar to peraluminous granites of other orogenic belts of Phanerozoic age. These type of granites are usually associated to rock generated by partial fusion of crustal sequences of pelitic composition with formation of a granulitic residue. Structural relations between the position of the granitic bodies and metamorphic evolution of the Brusque Metamorphic Complex associated to geochemical and geotectonic parameters are related to magmatism generator by anatexis connected to collisional event of the end of Brasiliano Cycle.
\end{abstract}

Keywords: Catarinense Shield, Tijucas Terrane, Brusque Metamorphic Complex, Peraluminous granites, Geochemistry.

1 - UFRGS, Instituto de Geociências, Centro de Estudos em Petrologia e Geoquímica. Porto Alegre ( RS), Brasil; Pesquisador do CNPq. E-mail: ruy.philipp@ufrgs.br

2 - UFRGS, Instituto de Geociências, Curso de Pós-Graduação em Geociências (PPGEO), Porto Alegre (RS), Brasil; Universidade Federal do Espírito Santo, Campus Universitário, Alegre (ES), Brasil.E-mail:beto_decampos@hotmail.com 
INTRODUÇÃ̃O O completo entendimento da evolução de um cinturão orogênico exige a integração da cartografia geológica de detalhe com análise petrográfica e estrutural. A partir da separação dos corpos e do estabelecimento das relações estratigráficas e espaciais, os estudos de química-mineral e termobarometria, levantamentos geoquímicos, isotópicos e geocronológicos são fundamentais para a caracterização dos protólitos. A identificação dos eventos magmáticos e metamórficos e de suas relações é um passo fundamental para compreender a construção do cinturão. A geração do magmatismo granítico pode estar associada a formação inicial do cinturão, vinculada a fase de subducção ativa, relacionada ao espessamento do orógeno durante a colisão continental ou ainda a uma fase posterior, de relaxamento e soerguimento crustal. O magmatismo granítico peraluminoso pode ser formado pela fusão crustal em porções profundas dos cinturões colisionais (White \& Chappell 1977; Winkler 1983: Patiño-Douce \& Johnston 1991; Stevens et al. 1997; Patiño-Douce \& McCarty 1998; Barbarin 1996), estar relacionado com a descompressão adiabática associada com o período pós-colisional (Liégeois 1998; Liégeois et al. 1998), ou ainda estar relacionado ao fracionamento de magmas básicos ou intermediários (Wilson 1989).

Novos dados estratigráficos, estruturais e metamórficos obtidos para a região compreendida entre as cidades de Itajaí e Tijucas, permitiram uma melhor compreensão sobre a origem e a superposição dos eventos metamórficos associados com a evolução do Complexo Metamórfico Brusque (CMB) (Bitencourt et al. inédito; Philipp et al. 2001a,b,c, 2004; Campos \& Philipp 2007). Durante estes levantamentos foram re- conhecidos corpos graníticos de natureza peraluminosa que ocorrem associados a evolução metamórfico-deformacional do referido complexo (Philipp et al. op.cit.).

O Complexo Metamórfico Brusque está localizado no Terreno Tijucas, na porção oeste do Cinturão Dom Feliciano em SC (Fig. 1). Apresenta uma disposição alongada segundo a direção $\mathrm{N} 45^{\circ} \mathrm{E}$ com cerca de 75 $\mathrm{km}$ de extensão e $45 \mathrm{~km}$ de largura, estando delimitado ao noroeste pela Zona de Transcorrência Itajaí-Perimbó e ao sudeste pela Zona de Cisalhamento Major Gercino, ambas estruturas de alta deformação dúctil (Fig. 2). O CMB é composto por um espesso pacote de metassedimentos clásticos, dominado por filitos e xistos micáceos intercalados com semipelitos, quartzitos, mármores e rochas calci-silicáticas, além de ocorrências restritas de rochas metavulcânicas de composição máfica a ultramáfica e leucogranitos peraluminosos (Sander 1992; Bitencourt et al. inédito; Philipp et al. 2004; Campos 2007; Campos \& Philipp 2007) (Fig. 3). Os principais corpos leucograníticos ocorrem na região de Itapema, estão deformados e apresentam formas tabulares concordantes com a xistosidade principal $\mathrm{S}_{2}$. A seção geológica esquemática da figura 4 apresenta uma visão geral das relações espaciais entre os corpos estudados. Os granitos possuem composição monzogranítica, cor esbranquiçada a rosada e estrutura bandada, subordinadamente, maciça, foliada e milonítica.

$\mathrm{Na}$ área estudada, as unidades do CMB são interrompidas pela intrusão dos granitóides brasilianos Compra Tudo (Bitencourt et al. inédito), Valsungana e Serra dos Macacos (Bitencourt et al. inédito). A intrusão destes corpos graníticos causa metamorfismo de contato e é responsável pela formação de zonas com

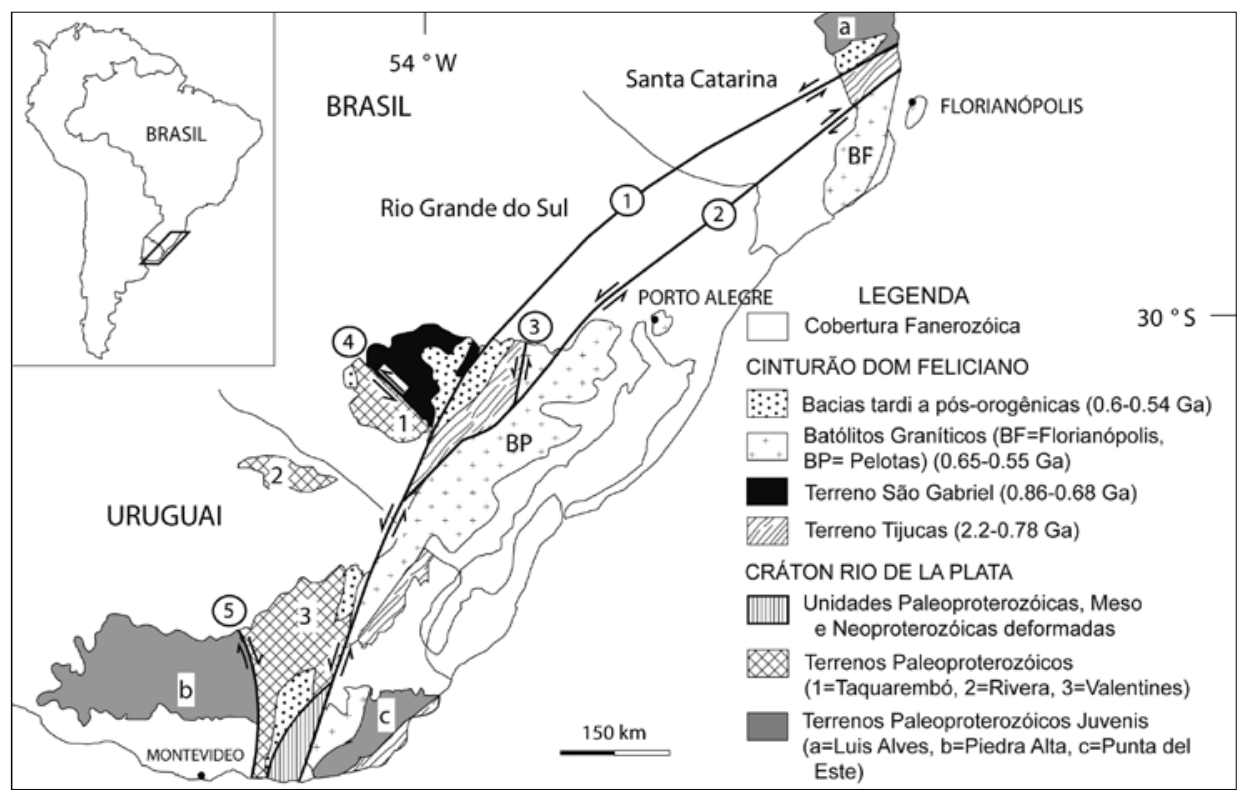

Figura 1 - Mapa da porção sul da Plataforma Sul Americana com as principais unidades geotectônicas. Legenda: $a=$ Terreno Luis Alves, $b=$ Terreno Florida $c=$ Terreno Punta del Este, $1=$ Terreno Taquarembó, $2=$ Terreno Rivera, $3=$ Terreno Valentines. (Modificado de Hartmann et al. 2007). 
mineralização de ouro na região de Tijucas e Canelinhas e na região do Ribeirão da Prata e Ribeirão do Ouro, em Botuverá (Silva \& Dias 1981; Caldasso et al.1995).

A tectônica deformadora do CMB está relacionada ao processo colisional de idade Brasiliana. Posteriormente, a atividade das zonas de cisalhamento dúcteis de alto ângulo e o metamorfismo de contato associado ao período pós-colisional, marcam o final do Ciclo Brasiliano nesta região.

A partir de novos dados de campo e petrográficos foram delimitados os corpos de leucogranitos que ocorrem na região de Itapema. As análises petrográficas reconheceram a natureza peraluminosa com a presença de muscovita e turmalina do tipo schorlita, associadas a biotita e granada almandina-espessartina. Os dados geoquímicos permitiram caracterizar a série magmática, enquanto as fontes do magmatismo e a correlação com o ambiente tectônico foram investigadas através da integração entre os dados de campo e os diagramas discriminantes e multi-elementares.

A idéia inicial de distinguir magmas de ambientes tectônicos diferentes com base na composição química de basaltos foi objeto de pesquisa por Pearce \& Cann (1971) Pearce et al. (1975), entre outros. Posteriormente, Pearce et al. (1984) e Pearce (1996) reconheceram a importância do uso dos diagramas utilizando elementos incompatíveis para a caracterização dos ambientes tectônicos das rochas granitóides. Mais recentemente, entretanto, os pesquisadores têm optado por uma análise integrada de dados petrográficos, estruturais, geoquímicos, isotópicos e geocronológicos para uma definição adequada do ambiente de formação das rochas.

Este trabalho tem como objetivo a caracterização petrográfica e geoquímica dos leucogranitos peraluminosos intrusivos no CMB na região de Itapema, em Santa Catarina. Para este fim foram empregadas técnicas de mapeamento geológico associado com petrografia (com ênfase para caracterização textural e microestrutural), dados estruturais e litogeoquímica.

MÉTODOS DE TRABALHO A etapa de campo teve como base o mapa geológico em escala 1:25.000 da Folha Camboriú, (Bitencourt et al. inédito). Novos dados foram obtidos a partir do mapeamento em escala 1:5.000, com a definição precisa da forma e limites dos corpos, bem como sobre as relações de contato com as rochas metamórficas encaixantes do CMB. Foram realizados perfis geológicos no costão norte e na porção central da praia de Itapema e na Serra da Miséria, com coleta de dados estruturais e estratigráficos e amostras para petrografia e geoquímica. As 15 lâminas petrográficas selecionadas foram descritas e fotografadas em microscópio petrográfico Zeiss modelo Axiolab.

Foram selecionadas 09 amostras de leucogranitos para estudos geoquímicos. As amostras selecionadas foram fragmentadas em prensa hidráulica e pulverizadas em moinho de ágata. Posteriormente, foram analisadas no Activations Laboratories (Canadá), por ICP-MS (Inductively Conductively Plasma, Mass

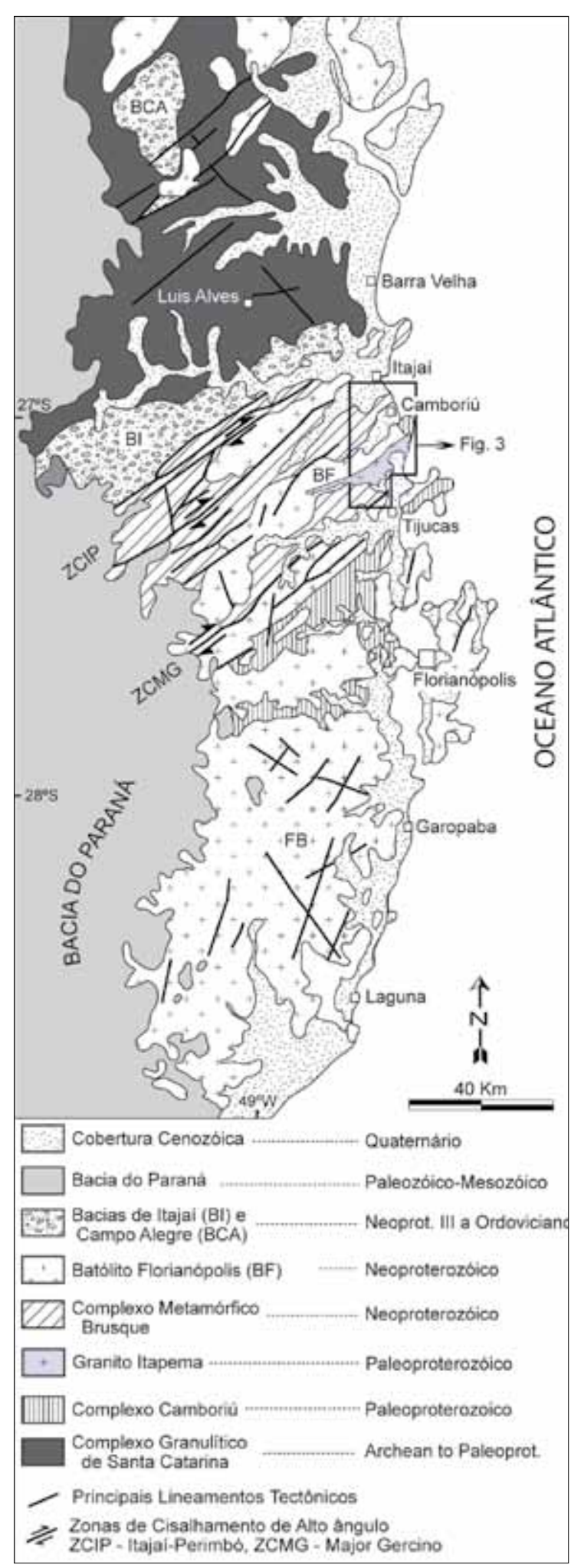

Figura 2 - Mapa do Escudo Catarinense destacando as principais unidades litoestratigráficas (Modificado de Philipp et al. 2004).

Spectrometry), para determinação dos óxidos de elementos maiores (erro $<0,01 \%$ ), elementos traços (erro $<1 \mathrm{ppm}$ ) e dos elementos terras raras (erro $<0,1 \mathrm{ppm}$ ). Os dados geoquímicos foram tratados por intermédio 


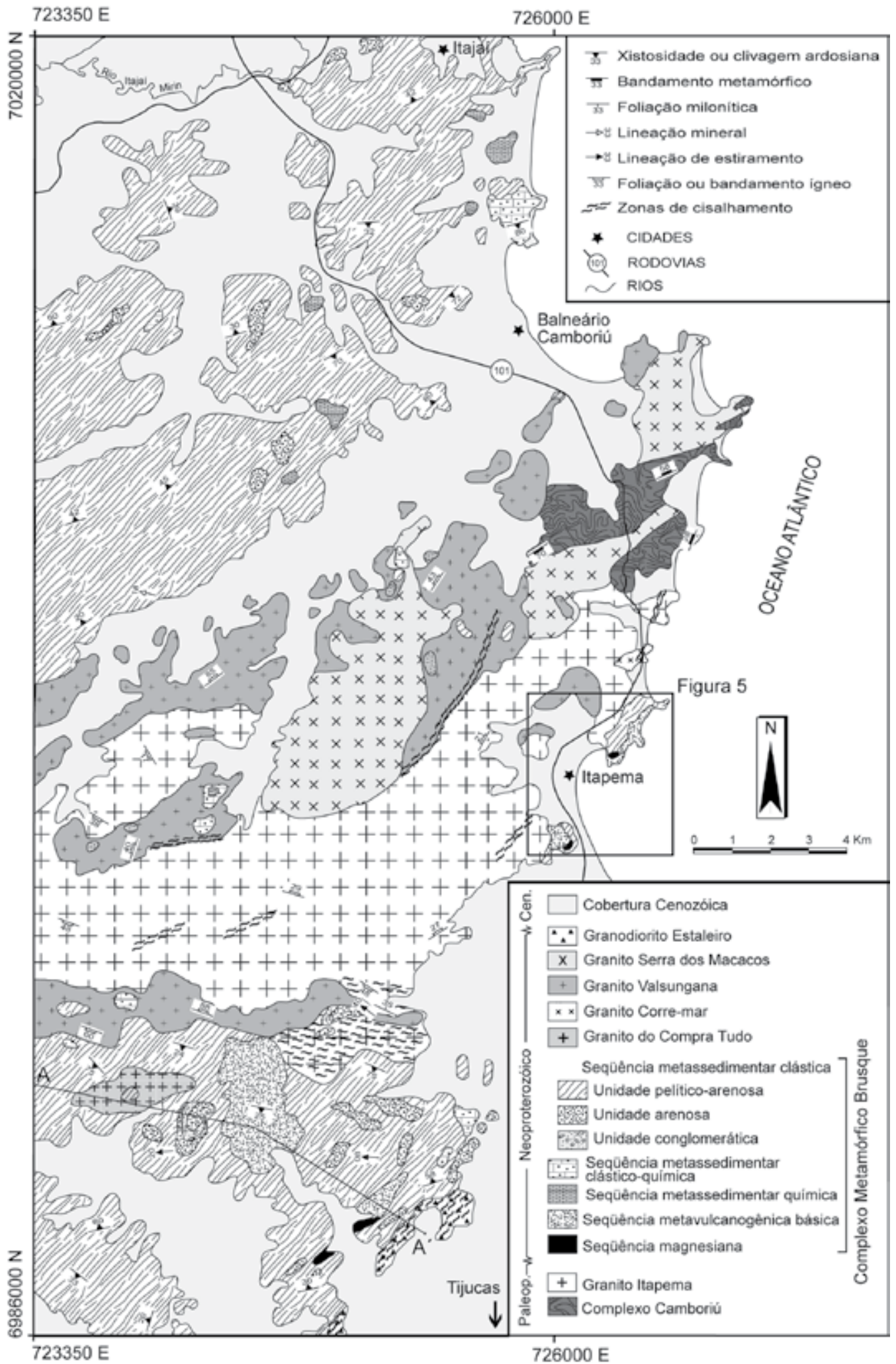

Figura 3 - Mapa geológico do Complexo Metamórfico Brusque na região entre Itajaí e Tijucas e localização da seção geológica da figura 4 e do mapa da figura 5 (modificado de Philipp et al. 2004).

dos programas Newpet e Minpet.

CONTEXTO GEOLÓGICO REGIONAL A ocorrência de granitos associados ao CMB tem sido descrita por diversos autores, que relacionaram estes corpos com o final da orogênese Brasiliana (Silva \& Dias 1981; Basei \& Teixeira 1987; Caldasso et al. 1995). Novos dados associados ao mapeamento geológico realizado por Bitencourt et al. (inédito) e Philipp et al. (2001c, 2004) permitiram o reconhecimento de granitóides 


\section{A-A') SEÇÃO GEOLÓGICA RIO CAMPO NOVO - SERTÃO DO VALONGO}

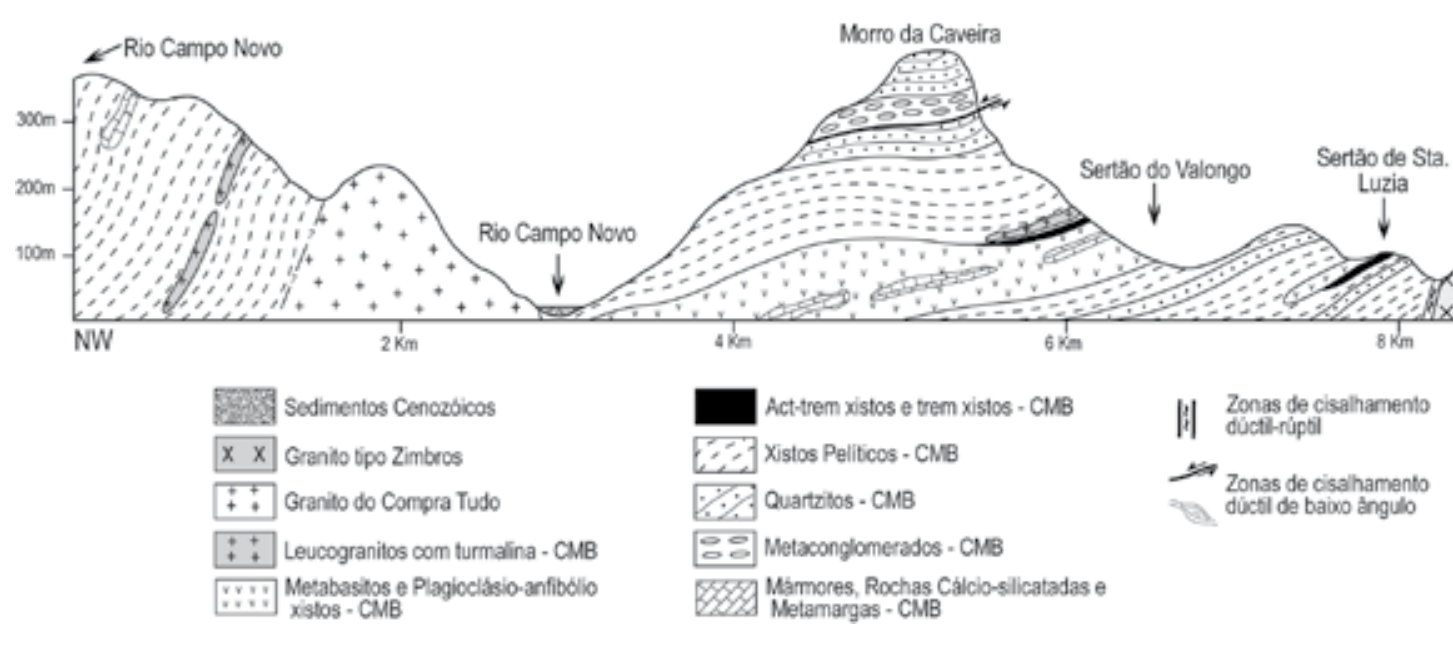

Figura 4 - Seção geológica esquemática Rio Campo Novo-Sertão do Valongo, mostrando a disposição espacial e os principais elementos estruturais das unidades do Complexo Metamórfico Brusque (modificado de Philipp et al. 2004).

mais antigos, com evolução e posicionamento associado as fases de deformação e metamorfismo que afetaram o CMB. Bitencourt \& Nardi (2004) descreveram o Granito Itapema, e embora não tenham observado relações de contato entre o granito e o CMB, sugerem que o referido granito é intrusivo no complexo. Hartmann et al. (2003) obtiveram uma idade magmática paleoproterozóica para o Granito Itapema a partir da datação geocronológica de zircões pelo método SHRIMP.

$\mathrm{O}$ período de sedimentação e vulcanismo e a idade do metamorfismo do CMB ainda não estão estabelecidos, e resultados conflitantes não permitem definir um quadro coerente da evolução temporal do complexo. Basei (1990), com base em determinações U-Pb convencional em zircões detríticos de xistos pelíticos sugere um intervalo de 1500 a 2000 Ma para a sedimentação do $\mathrm{CMB}$, indicando uma idade $\mathrm{Nd}\left(\mathrm{T}_{\mathrm{DM}}\right)$ de $1670 \mathrm{Ma}$, obtida em rocha metavulcânica básica do Complexo, como o limite inferior de sedimentação do mesmo. Os dados U-Pb SHRIMP obtidos por Hartmann et al. (2003) em zircões detríticos de quartzitos do CMB indicam que a sedimentação da bacia é mais jovem que $2023 \pm 7 \mathrm{Ma}$. As idades U-Pb em zircão de $835 \pm 9 \mathrm{Ma}$ (método TIMS) e $843 \pm 12 \mathrm{Ma}$ (método SHRIMP) foram apontadas por Basei et al. (2008) como os valores mínimos para a sedimentação do Complexo Brusque. Estas idades representam a cristalização do Granito do Morro do Parapente, descrito na região de Gaspar. Este magmatismo da série alcalina foi interpretado como sendo gerado em um sistema de ritf continental que originou a bacia preenchida pelos metassedimentos do Complexo Brusque.

A idade do metamorfismo, com valor de 706 Ma (Rb-Sr, rocha total), obtido por Basei \& Teixeira (1987) é interpretada por Basei (1990) como a idade mais representativa do clímax metamórfico do $\mathrm{CMB}$, correspondendo à segunda fase de metamorfismo $\left(\mathrm{M}_{2}\right)$ em paragnaisses. Tickyj et al. (2004) obtiveram através da determinação da composição química da monazita por microssonda eletrônica, uma idade de $545 \pm 55 \mathrm{Ma}$ para os leucogranitos estudados.

$\mathrm{Na}$ região de Itapema-Tijucas foram reconhecidas quatro fases de deformação $\left(\mathrm{D}_{1}\right.$ a $\left.\mathrm{D}_{4}\right)$ na evolução estrutural do $\mathrm{CMB}$, superimpostas a partir da superfície sedimentar So, gerando as superfícies $\mathrm{S}_{1}-\mathrm{S}_{4}$ (Philipp et al. 2001c, 2004). As duas primeiras fases são caracterizadas por estruturas de baixo ângulo, relacionadas a um evento de colisão oblíqua, gerando estruturas dúcteis em temperaturas compatíveis com as da fácies xisto verde inferior a anfibolito inferior. As duas últimas estão relacionadas ao desenvolvimento das zonas de cisalhamento transcorrente gerando estruturas dúctilrúpteis acompanhada por metamorfismo de fácies xisto verde. A fase de deformação $\mathrm{D}_{1}$ está preservada na maioria das litologias como dobras $\mathrm{F}_{2}$ intrafoliais, apertadas a isoclinais. A xistosidade $\mathrm{S}_{2}$ representa a principal foliação regional e mostra direção predominante $\mathrm{N} 30^{\circ} \mathrm{E}$ com mergulho de baixo ângulo para noroeste e sudeste. A fase $\mathrm{D}_{3}$ gerou dobras $\mathrm{F}_{3}$ assimétricas, com formas abertas a fechadas e superfície axial subvertical marcada por uma clivagem de crenulação incipiente e/ ou por uma clivagem de fratura com direção $\mathrm{N} 45^{\circ} \mathrm{E}$, subvertical. A fase de deformação $\mathrm{D}_{4}$ está marcada por dobras $\mathrm{F}_{4}$ abertas do tipo kink e chevron, com uma clivagem de fratura plano-axial $\mathrm{S}_{4}$ de direção NW.

Os eventos $M_{1}$ e $M_{2}$ são relacionados ao metamorfismo orogênico de baixa pressão, ocorrendo concomitantes com o desenvolvimento das foliações $\mathrm{S}_{1}$ e $\mathrm{S}_{2}$, ambas estruturas geradas durante o evento colisional no fim do Ciclo Brasiliano (Caldasso et al. 1995; Philipp et al. 2004). As condições de temperatura evoluem da fácies xisto verde a anfibolito inferior, e possuem um padrão de zonação complexo, que varia desde a zona da clorita, passando para biotita, granada, andaluzita e cordierita. As zonas mostram disposição 
subparalela em relação a xistosidade, com a repetição de zonas de baixa temperatura no interior de zonas de temperatura mais alta, indicando a intercalação tectônica de fatias da seqüência metamórfica (Philipp et al. 2004). O evento $M_{3}$ está associado ao posicionamento sintranscorrência $\left(\mathrm{D}_{3}\right)$ dos granitóides Valsungana e Serra dos Macacos, e desenvolve auréola de metamorfismo de contato, com cornubianitos pelíticos e calci-silicáticos apresentando assembléias minerais indicativas de condições metamórficas da fácies albita-epidoto cornubianito a piroxênio cornubianito. Esta auréola atinge extensões variáveis entre 300 a 1500 m e sugere que o posicionamento dos granitos ocorreu em níveis mais profundos da crosta superior (Caldasso et al. 1995; Philipp et al. 2004).

\section{ASPECTOS GEOLÓGICOS DOS LEUCOGRANI-}

TOS Os principais leucogranitos estudados ocorrem no costão norte de Itapema (Ponta do Engodo, Ponta Grossa e a Ponta da Ilhota) e na, porção central de Itapema (Meia Praia), com exposições restritas na região do Sertão do Valongo. Destas exposições somente os corpos do costão norte de Itapema conseguiram ser representados na escala de mapeamento (Fig. 5).
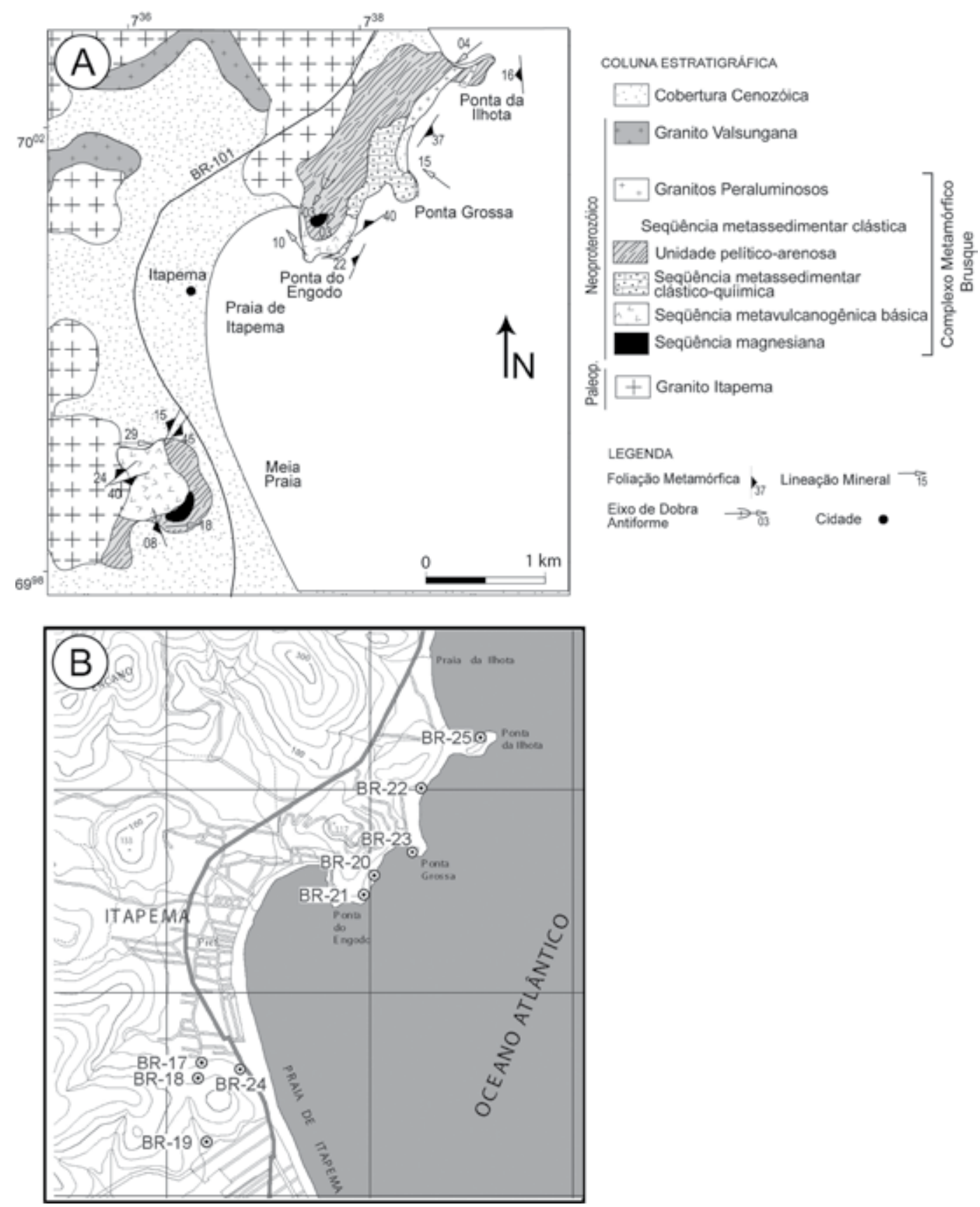

Figura 5 - A) Mapa geológico da região de Itapema, destacando a localização do principal corpo de leucogranito estudado; B) Mapa de localização das amostras com análises geoquímicas e petrográficas. 
Sertão do Valongo No Sertão do Valongo os leucogranitos ocorrem como corpos tabulares com disposição suborizontal, intercalados com os metapelitos (Fig. 4). Estes corpos apresentam em planta uma forma alongada segundo a direção $\mathrm{N} 20^{\circ} \mathrm{E}$, aflorando com cerca de 15 a 20 m de extensão e 1-5 metros de espessura. Os granitos estão alterados, apresentam cor esbranquiçada a rosada, aspecto maciço a pouco foliado e textura equigranular média (2 a $5 \mathrm{~mm}$ ). A mineralogia é composta por K-feldspato, plagioclásio, quartzo, com pouca turmalina e muscovita.

Costão Norte de Itapema No costão norte de Itapema, entre a Ponta do Engodo e a Ponta da Ilhota, ocorrem as principais exposições dos leucogranitos estudados. Os corpos têm forma tabular e são concordantes com a xistosidade regional dos xistos máficos e calci-silicáticos do CMB. O maior dos corpos entre a Ponta Grossa e a Ponta da Ilhota, aflora a partir da metade da praia em direção ao norte. Possui forma tabular orientada segundo a direção $\mathrm{N} 35^{\circ} \mathrm{E}$, com 400 metros de extensão e 6 e 10 metros de espessura (Figs. 5 e $6 \mathrm{a}$ ). O granito apresenta um bandamento magmático caracterizado pela alternância regular e contínua de níveis com textura equigranular média a grossa $(2$ a $10 \mathrm{~mm})$ e níveis com textura pegmatitíca, com cristais de ordem de 5 a 10 centímetros (Figs. $6 \mathrm{~b}$ e $6 \mathrm{c}$ ). As bandas mostram espessuras centimétricas $(5 \mathrm{a} 25 \mathrm{~cm})$ e estrutura interna pouco foliada a maciça. $\mathrm{O}$ bandamento é formado pelo preenchimento de fraturas por injeções sucessivas. A mineralogia principal é composta por K-feldspato, plagioclásio e quartzo com ocorrência subordinada de biotita, muscovita, turmalina e granada. São comuns veios e injeções ricas em quartzo e turmalina ou somente de turmalina. Apresentam disposição concordante a discordante, limites retos a pouco curvilíneos e espessuras variáveis entre 1 e 10 centímetros.

Os corpos da Ponta do Engodo possuem espessura entre 10 e 40 centímetros e forma tabular. Estão deformados pela foliação $\mathrm{S}_{2}$, mostrando-se boudinados quando subparalelos com a foliação e dobrados quando dispostos em ângulo elevado com relação a xistosidade $\mathrm{S}_{2}$ (Fig. 6d). Os contatos são nítidos, com limites curvilíneos a pouco retilíneos. As injeções causam hidratação nos xistos máficos próximos a zona de contato, formando finas faixas de epidoto com clorita associada. Os granitos mostram foliação incipiente ocorrendo um corpo granítico deformado por uma zona de cisalhamento dúctil de baixo ângulo com orientação mineral proeminente. Possui espessura inferior a 1 metro e textura milonítica com pronunciada lineação de estiramento definida por porfiroclastos de feldspato e quartzo. A mineralogia é composta por K-feldspato, plagioclásio e quartzo, com turmalina e muscovita. Os corpos de granito estão cortados por veios de quartzo e turmalina e por turmalinitos. Os primeiros constituem corpos em geral discordantes associados a porções pegmatóides e freqüentemente encontram-se dobrados. Possuem cor esbranquiçada com espessuras entre 2 e $10 \mathrm{~cm}$ e são compostos por quartzo com turmalina associada. Os turmalinitos possuem cor preta, espessuras entre 1 e $3 \mathrm{~cm}$ e mostram disposição aproximadamente paralela ao bandamento dos corpos graníticos (Fig. 6e). Os cristais de turmalina têm forma alongada e mostram um crescimento sintaxial, com disposição perpendicular as paredes da fratura.

Meia Praia (Itapema) Os leucogranitos que ocorrem na Meia Praia constituem três corpos com forma tabular e espessuras entre 50 centímetros e 1,5 metros com cerca de 20 a 40 metros de extensão aflorante. Os principais afloramentos são cortes de estrada na BR-101. As injeções estão intercaladas com cordierita-muscovita xistos e, menos freqüente, com xistos máficos. Os corpos estão concordantes com a xistosidade regional de direção $\mathrm{N} 40^{\circ} \mathrm{E}$ e mostramse boudinados e dobrados pelas fases de dobramento $\mathrm{F}_{2}$ e $\mathrm{F}_{3}$. Os granitos têm cor branca e estrutura bandada, semelhantes aos do costão norte de Itapema. Mostram uma composição rica em feldspatos e quartzo, com presença subordinada de muscovita e turmalina.

Condições de Posicionamento A presença de texturas equigranular média a grossa, a superposição por uma foliação milonítica e a presença de rochas encaixantes de baixo a médio grau metamórfico é sugestiva que os granitos representem injeções posicionadas em níveis intermediários da crosta. $\mathrm{O}$ granito apresenta uma foliação de forma marcada pela orientação dimensional de feldspatos, muscovita, turmalina e alongamenrto de quartzo. Esta foliação magmática é superposta por uma foliação milonítica concordante. Observam-se também feições de deformação em estado subsolidus, como encurvamento de maclas, formação de subgrãos com limites interlobados e maclas de deformação no quartzo do tipo chessboard. Estas observações sugerem uma transição entre as estruturas magmáticas e tectônicas, indicando a contemporaneidade entre a colocação dos corpos e a atuação das fases de deformação do CMB. Os corpos mostram disposição suborizontal, concordantes com a xistosidade regional, orientados em planta segundo a direção $\mathrm{N} 30-40^{\circ} \mathrm{E}$ (Fig. 6f). Menos freqüentemente, também se observam corpos menores, de espessura centimétrica ( 5 a $20 \mathrm{~cm}$ ), com disposição discordante, geralmente em ângulo alto com relação a xistosidade regional (Fig. 7a). Esta relação sugere um posicionamento simultâneo, controlado pela mesma fase de deformação regional, com os corpos injetando superfícies axiais de dobras $\mathrm{F}_{2}$ e, subordinadamente, pequenos corpos discordantes, associados a fraturas de extensão do mesmo evento.

As relações de campo mostram que os corpos estão deformados e concordantes com a xistosidade regional $\mathrm{S}_{2}$. Nas exposições da Meia Praia e nas Pontas do Engodo e da Ilhota, as injeções graníticas posicionamse na superfície axial das dobras $F_{2}$ (Fig. 7b). Estas relações sugerem que os corpos se posicionaram durante a formação da $\mathrm{S}_{2}$ e continuaram sendo deformados como indicado pela boudinage e pelo dobramento localizado das pequenas injeções discordantes. Estas relações vinculam a colocação dos granitóides com segunda fase de metamorfismo e deformação regional do Complexo 

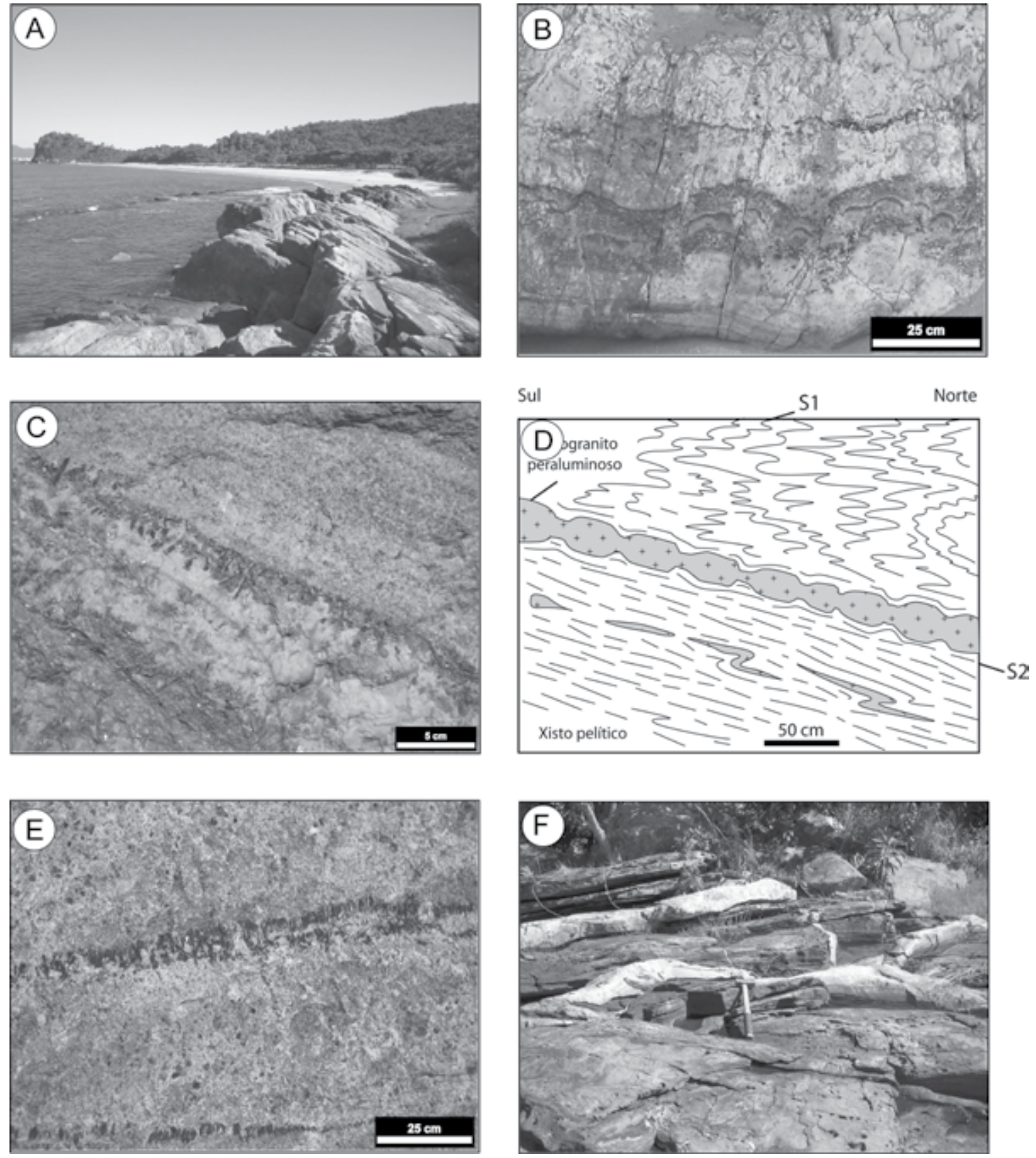

Figura 6 - Principais feições estruturais do leucogranitos estudados. A) Corpo principal de leucogranito entre a Ponta Grossa e a Ponta da Ilhota, realçando sua disposição tabular e concordante com a xistosidade regional (S2); B) Afloramento da Ponta da Ilhota, destacando o bandamento magmático dos leucogranito; $C$ ) Detalhe do bandamento magmático alternando niveis de textura equigranular fina e grossa, ressaltando o crescimento sintaxial de turmalina, BR-101, Itapema; D) Croqui esquemático de corpos graniticos que ocorrem na Ponta do Engodo e que estão deformados pela foliação $S 2$; E) Veios de turmalinitos, ressaltando o crescimento sintaxial de turmalina e quartzo, Ponta da Ilhota; F) Injeções de corpos tabulares de leucogranitos concordantes a xistosidade regional S2, Ponta do Engodo.

Metamórfico Brusque.

Estes dados ressaltam a diferença temporal entre os leucogranitos e os demais granitóides que cortam o complexo. Além das relações estruturais, os Granitos Compra Tudo (Bitencourt et al. inédito), Valsungana, Serra dos Macacos (Bitencourt et al. inédito) e Guabiruba cortam de modo discordante as foliações $\mathrm{S}_{1}$ e $\mathrm{S}_{2}$ e causam metamorfismo de contato nas unidades do complexo (Caldasso et al. 1995; Bitencourt et al. inédito; Philipp et al. 2001a, 2004). As paragêneses identificadas nas aureólas indicam que os granitóides posicionaramse sob condições de pressão inferiores ou iguais a 3 Kbares, e portanto, em um nível da crosta superior. Os dados estruturais apresentados por Philipp et al. (2001c) 

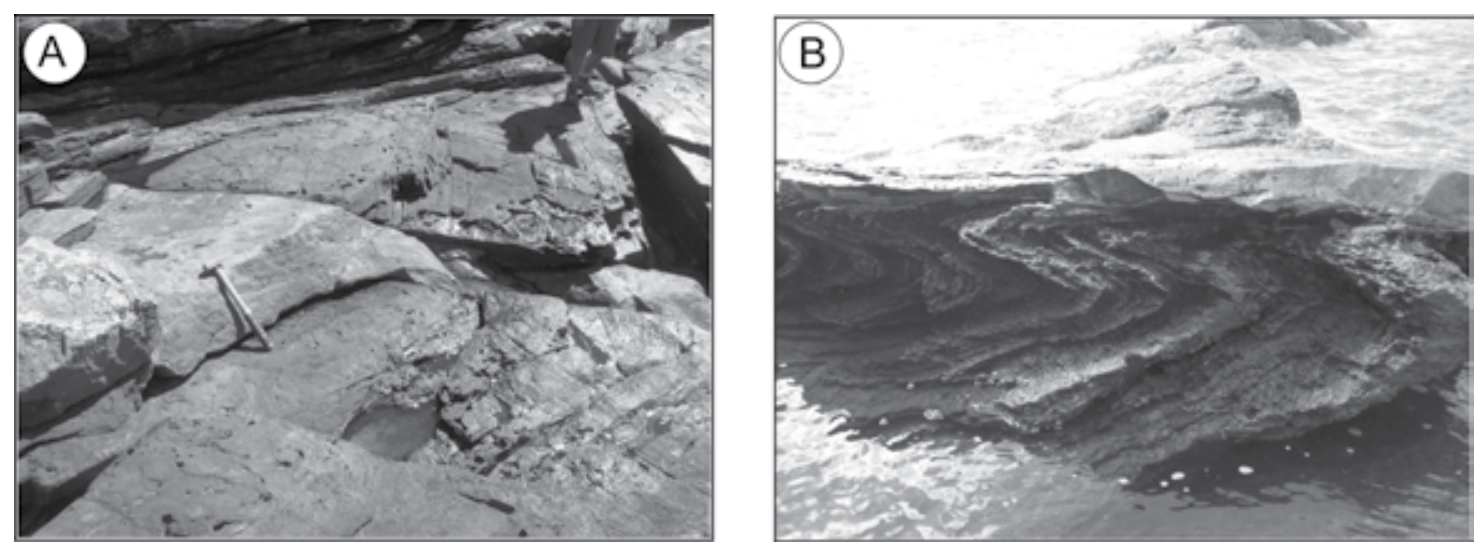

Figura 7 - Relações estruturais entre os leucogranitos e o Complexo Metamórfico Brusque. A) Detalhe de parte de uma injeção de leucogranito discordante com relação a xistosidade regional S2, mesmo afloramento da figura $6 F$; B)Injeção de corpo tabular concordante com a superficie axial de dobra isoclinal F2, Ponta da Ilhota.

indicam que a atitude média da xistosidade regional $\mathrm{S}_{2}$ é N60-70 $\mathrm{E}$, com mergulhos para noroeste e subordinadamente, para sudeste. Esta variação da atitude do mergulho foi interpretada como uma conseqüência da fase de dobramentos $\mathrm{D}_{3}$, que provavemente é o resultado da instalação e movimentação das zonas de cisalhamento Itajaí-Perimbó e Major Gercino. A superfície axial destas dobras é concordante com as principais zonas de cisalhamento transcorrentes que delimitam o CMB e que controlaram o posicionamento dos granitos Valsungana, Serra dos Macacos e Guabiruba (Philipp et al. 2001, 2004). A relação entre as atitudes médias da foliação regional e da lineação mineral levou os autores acima a sugerir que a evolução tectônica do complexo esteja relacionada a um processo de colisão oblíqua.

\section{PETROGRAFIA}

Leucogranitos Os leucogranitos apresentam estrutura bandada intercalando níveis com textura equigranular-hipidiomórfica de diferentes granulações, desde fina, média até grossa $(2-10 \mathrm{~mm})$ e níveis com textura muito grossa a pegmatítica $(1 \mathrm{a} 10 \mathrm{~cm})$. As porções equigranulares são compostas por quartzo, $\mathrm{K}$-feldspato e plagioclásio, com presença subordinada de muscovita, biotita, turmalina e granada. Os níveis mais grossos e pegmatóides mostram teores mais elevados de muscovita e turmalina, sem granada. $\mathrm{O}$ contato entre as bandas é bem definido e tem formas retilíneas a pouco curvilíneas. As bandas de textura pegmatóide são zonadas, apresentando uma porção externa rica em turmalina $\mathrm{e}$ muscovita e/ou biotita, com uma porção central com teores elevados de feldspatos e quartzo, acompanhados por muscovita (Figs. 8a,b). Os cristais de turmalina e muscovita da porção externa mostram crescimento sintaxial, com alongamento principal perpendicular a zona de contato. Esta feição indica que a zonação é resultado de sucessivas injeções magmáticas a partir de diversas aberturas de uma mesma fratura. Subordinadamente apresentam estrutura foliada de origem magmática, definida pela orientação dimensional de K-feldspato, pla- gioclásio e turmalina, alongamento de quartzo.

A composição é dominantemente monzogranítica, embora ocorram termos sienograníticos (Fig. 9). Os principais minerais constituintes são K-feldspato, plagioclásio, quartzo, muscovita, biotita e turmalina, ocorrendo granada, monazita, zircão, apatita e minerais opacos como acessórios (Tab. 1). O epidoto e a clorita são raros e se encontram principalmente nas zonas de contato de algumas injeções com os xistos máficos, preenchendo veios ou nas bordas e núcleos do plagioclásio e/ou hornblenda.

O plagioclásio tem cor branca a cinza clara, forma prismática pouco alongada, subédrico, com tamanhos entre $1 \mathrm{a} 4 \mathrm{~mm}$. Apresenta macla polissintética, estão zonados e mostra contatos suturados a retos. Contém inclusões de turmalina e zircão. Em porções de bordo de algumas bandas ocorre intercrescido com o quartzo de forma vermiforme constituindo a textura granofírica. O $\mathrm{K}$-feldspato tem cor rosa a cinza clara, forma prismática, subédrico, tamanhos entre 2 e 10 $\mathrm{mm}$, podendo atingir até $10 \mathrm{~cm}$. Possui macla Carlsbad e xadrez (Ab-Periclíneo). Em porções externas de certas bandas apresenta forma vermiforme e ocorre associado ao quartzo constituindo a textura micrográfica. Os feldspatos estão pouco fraturados e apresentam crescimento irregular de sericita. O quartzo é incolor e constitui grãos com forma amebóide e alongada, variando de $1 \mathrm{a} 3 \mathrm{~mm}$. Possui raras inclusões de turmalina. A muscovita é o principal mineral subessencial, apresentando cor cinza prateada, forma hexagonal e subédrica. Ocorre em agregados e de modo intersticial, variando de 0,2 a $4 \mathrm{~mm}$, podendo chegar a $5 \mathrm{~cm}$ nas porções pegmatíticas. A turmalina do tipo Schorlita ocorre em todos os corpos. Mostra cor preta, forma prismática alongada, euédrica a subédrica, na forma de agregados e cristais isolados intersticiais, em proporções variadas. Ocorre também inclusa em plagioclásio, K-feldspato e quartzo. Possui tamanhos entre 0,2 a $5 \mathrm{~mm}$, atingindo até $7 \mathrm{~cm}$ nos pegmatóides. Ao microscópio mostra zonação bem definida, com cor verde azulada e pleocro- 

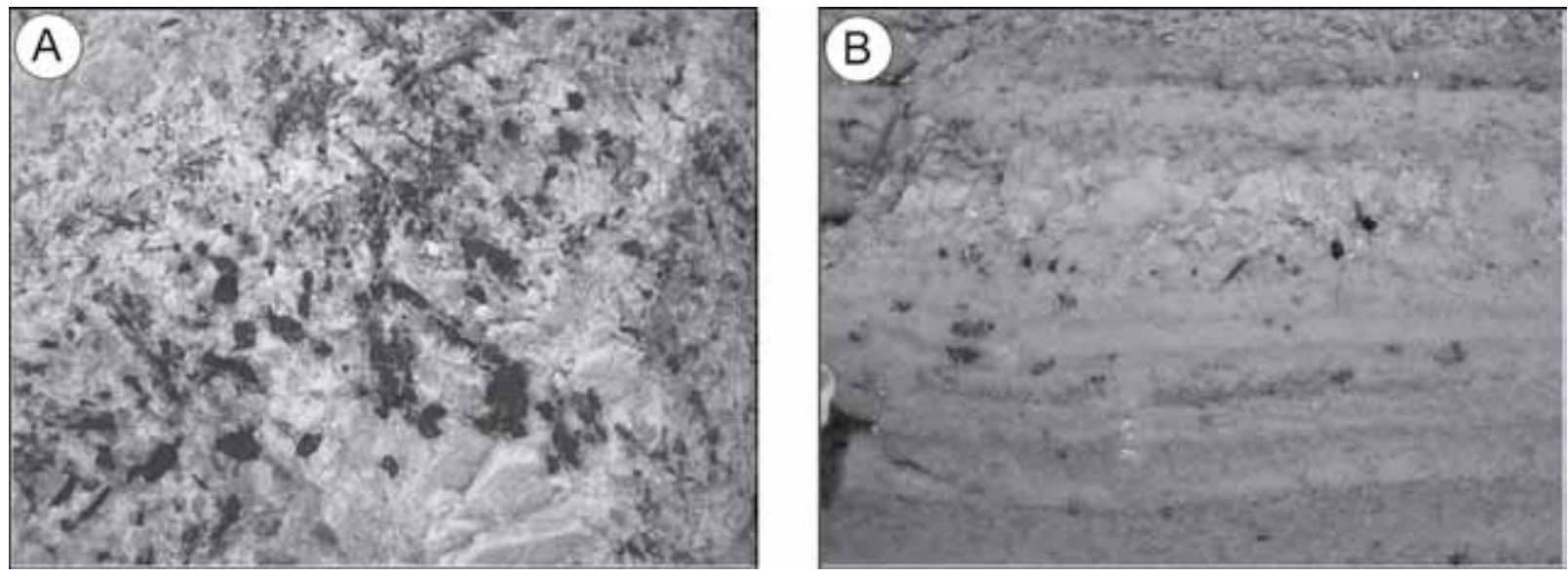

Figura 8 - Aspecto macroscópico do leucogranito. A) Textura equigranular grossa composta por quartzo, feldspato e turmalina, Ponta da Ilhota; B) Detalhe do bandamento magmático caracterizado pela diferença de tamanho de grão e composição mineralógica, Ponta da Ilhota.

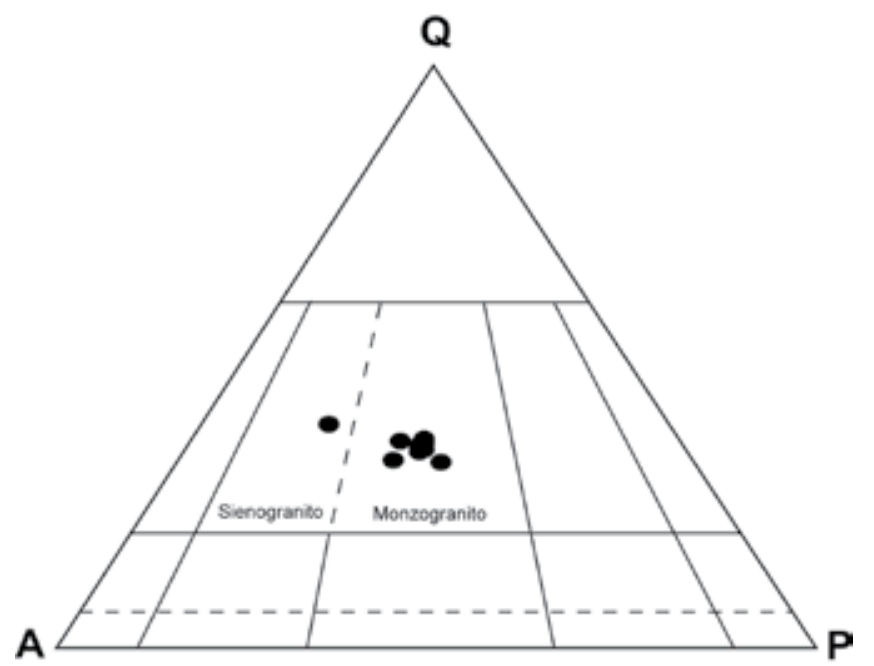

Figura 9 - Diagrama QAP de classificação dos leucogranitos (Streckeisen 1976).

ísmo variando de azul esverdeado a roxo. A granada é rara e ocorre somente nos termos equigranulares finos a médios, com forma globular, cor laranja a castanho avermelhada, subédrica, intersticial, com tamanhos entre 0,5 a $2 \mathrm{~mm}$. A biotita é rara, ocorrendo junto com a turmalina constituindo agregados em algumas bandas de granito equigranular grosso a muito grosso. Possui cor preta, forma hexagonal subédrica e tamanhos entre 3 e $10 \mathrm{~mm}$. Os minerais opacos são raros, possuem forma octaédrica, subédricos, de tamanhos entre 0,3 a 1 $\mathrm{mm}$.

A maioria das amostras apresenta textura protomilonítica, caracterizada pelo estiramento de quartzo, muscovita e K-feldspato, com fragmentação do plagioclásio, granada e turmalina. O quartzo está sempre deformado, com subgrãos de formas variadas, limites irregulares, lamelas de deformação e forte extinção on- dulante. Também mostra maclas do tipo chessboard, indicando deformação contemporânea com o resfriamento da rocha. Comumente mostram forma alongada e elevado grau de recristalização parcial, entre 25 a $45 \%$, formando mosaicos granoblásticos poligonais de grão fino a médio nos bordos e ao longo dos limites dos subgrãos. O K-feldspato apresenta encurvamento de maclas e formação de subgrãos. De modo localizado, apresentam recristalização ao longo dos limites dos subgrãos para agregados granoblásticos finos de limites interlobados a serrilhados. O plagioclásio está pouco deformado, mostrando encurvamento de maclas, fragmentação e extinção ondulante. A deformação da muscovita forma cristais do tipo fish, com terminações alongadas. A turmalina e a granada mostram intenso fraturamento. As feições microestruturais e texturais observadas nos feldspatos e no quartzo são indicativas da atuação de processos de deformação dúcteis desenvolvidos sob condições metamórficas equivalentes as da fácies xisto verde superior a anfibolito inferior.

Veios de Quartzo e Turmalina Os veios de quartzo possuem proporções variadas de turmalina, entre $10 \mathrm{e}$ $25 \%$, que ocorre como agregados irregulares de cristais alongados de cor preta, formas prismáticas subédricas e tamanhos entre 2 e $30 \mathrm{~mm}$. O quartzo é homogêneo e apresenta-se deformado com extinção ondulante e formação de subgrãos.

Turmalinitos Os turmalinitos são compostos dominantemente por turmalina preta do tipo schorlita com proporções de quartzo, entre 10 e $20 \%$. Os cristais de turmalina variam de 2 a $15 \mathrm{~mm}$, tem forma alongada, são euédricos a subédricos e mostram um crescimento sintaxial. O quartzo é incolor e amebóide.

LITOGEOQUíMICA A composição dos elementos maiores e traços de nove amostras representativas dos leucogranitos são apresentadas nas tabelas 2 e 3 . Os 
Tabela 1 - Análises modais representativas dos minerais constituintes dos leucogranitos estudados.

\begin{tabular}{|c|c|c|c|c|c|c|c|c|c|c|c|}
\hline Miner/Amostras & BR-12 & BR-19 & BR20C & BR21D & BR-22 & BR22B & BR-24 & BR24a & $\mathrm{BR} 25 \mathrm{C}$ & $\mathrm{Br} 22 \mathrm{Qz}$ & $\mathrm{Br} 22 \mathrm{Tr}$ \\
\hline K-feldspato & 31 & 29 & 36 & 34 & 30 & 29 & 29 & 32 & 34 & --- & --- \\
\hline Plagioclásio & 28 & 26 & 14 & 25 & 28 & 27 & 31 & 30 & 26 & --- & --- \\
\hline Quartzo & 30 & 29 & 31 & 28 & 31 & 31 & 28 & 32 & 33 & 82 & 15 \\
\hline Muscovita & 4 & 6 & 7 & 4 & 1 & 5 & 3 & 7 & 4 & $1-2$ & --- \\
\hline Turmalina & 5 & 4 & 12 & 6 & 12 & 3 & 4 & $\mathrm{Tr}$ & 2 & 16 & 85 \\
\hline Biotita & 2 & --- & --- & --- & --- & $3-4$ & --- & --- & --- & --- & --- \\
\hline Granada & --- & --- & --- & 3 & --- & --- & --- & 1 & --- & --- & --- \\
\hline Monazita & $\mathrm{Tr}$ & $\mathrm{Tr}$ & $\mathrm{Tr}$ & $\mathrm{Tr}$ & $\mathrm{Tr}$ & $\mathrm{Tr}$ & $\mathrm{Tr}$ & $\mathrm{Tr}$ & $\mathrm{Tr}$ & --- & --- \\
\hline Apatita & --- & $\mathrm{Tr}$ & $\mathrm{Tr}$ & $\mathrm{Tr}$ & $\mathrm{Tr}$ & $\mathrm{Tr}$ & $\mathrm{Tr}$ & $\mathrm{Tr}$ & $\mathrm{Tr}$ & --- & $\begin{array}{ll}-- \\
\end{array}$ \\
\hline Zircão & --- & $\mathrm{Tr}$ & $\mathrm{Tr}$ & $\mathrm{Tr}$ & $\mathrm{Tr}$ & $\mathrm{Tr}$ & $\mathrm{Tr}$ & $\mathrm{Tr}$ & $\mathrm{Tr}$ & --- & $\begin{array}{l}-- \\
\end{array}$ \\
\hline Minerais Opac. & --- & $\mathrm{Tr}$ & --- & $\mathrm{Tr}$ & --- & $\mathrm{Tr}$ & --- & --- & $\mathrm{Tr}$ & --- & $\begin{array}{c}-- \\
\end{array}$ \\
\hline Epidoto & --- & 2 & --- & --- & --- & --- & --- & --- & --- & --- & $\begin{array}{ll}-- \\
\end{array}$ \\
\hline Clorita & --- & 1 & --- & --- & --- & $\begin{array}{l}-- \\
\end{array}$ & --- & --- & --- & --- & $\begin{array}{l}-- \\
\end{array}$ \\
\hline Sericita & --- & 1 & 1 & $\mathrm{Tr}$ & $\mathrm{Tr}$ & --- & --- & --- & 1 & --- & --- \\
\hline Classificação & Monz & Monz & Sien & Monz & Monz & Monz & Monz & Monz & $\begin{array}{l}\text { Monz } \\
\text { milon. }\end{array}$ & $\begin{array}{l}\text { Veio de } \\
\text { Qz-Tur }\end{array}$ & Turm \\
\hline
\end{tabular}

Classificação: Monz - monzogranito, Sien - sienogranito, milon.- milonítico, Turm - Turmalinito.

Tabela 2 - Composição representativa dos elementos maiores (\% de peso) de amostras selecionadas dos leucogranitos.

\begin{tabular}{c|c|c|c|c|c|c|c}
\hline Amostras & BR-20C & BR-22 & BR-22A & BR-23D & BR-23G & BR-21B & BR-24 \\
\hline $\mathrm{SiO}_{2}$ & 73.9 & 73.95 & 75.2 & 75.31 & 75.57 & 75.66 & 76.24 \\
\hline $\mathrm{Al}_{2} \mathrm{O}_{3}$ & 15.1 & 14.65 & 14.58 & 14.25 & 13.78 & 14.4 & 14.34 \\
\hline $\mathrm{Fe}_{2} \mathrm{O}_{3}(\mathrm{t})$ & 0.69 & 0.92 & 0.75 & 0.2 & 0.21 & 0.59 & 0.54 \\
\hline $\mathrm{MnO}$ & 0.01 & 0.111 & 0.032 & 0.011 & 0.006 & 0.054 & 0.025 \\
\hline $\mathrm{MgO}$ & 0.35 & 0.15 & 0.11 & 0.1 & 0.12 & 0.08 & 0.1 \\
\hline $\mathrm{CaO}$ & 1.6 & 0.52 & 0.47 & 1.87 & 0.95 & 0.59 & 0.8 \\
\hline $\mathrm{Na}_{2} \mathrm{O}$ & 3.97 & 4.24 & 3.92 & 3.91 & 3.45 & 4.04 & 3.18 \\
\hline $\mathrm{K}_{2} \mathrm{O}$ & 3.57 & 3.76 & 4.47 & 3.36 & 5.63 & 4.55 & 4.46 \\
\hline $\mathrm{TiO}_{2}$ & 0.046 & 0.043 & 0.04 & 0.012 & 0.035 & 0.025 & 0.039 \\
\hline $\mathrm{P}_{2} \mathrm{O}_{5}$ & 0.28 & 0.15 & 0.19 & 0.15 & 0.16 & 0.13 & 0.14 \\
\hline $\mathrm{LOI}$ & 0.8 & 0.95 & 1.05 & 0.57 & 0.63 & 0.51 & 0.73 \\
\hline $\mathrm{Total}$ & 100.3 & 99.44 & 100.8 & 99.74 & 100.5 & 100.6 & 100.6 \\
\hline & & & & & & & \\
\hline $\mathrm{K}_{2} \mathrm{O} / \mathrm{Na}_{2} \mathrm{O}$ & 0.89 & 0.88 & 1.14 & 0.85 & 1.63 & 1.12 & 1.4 \\
\hline $\mathrm{CaO} / \mathrm{Na}_{2} \mathrm{O}$ & 0.40 & 0.12 & 0.11 & 0.47 & 0.27 & 0.14 & 0.25 \\
\hline $\mathrm{Al}_{2} \mathrm{O}_{3} / \mathrm{TiO}_{2}$ & 328.3 & 340.7 & 364.5 & 1187 & 393.7 & 576 & 367.6 \\
\hline & & & & & &
\end{tabular}

leucogranitos mostram conteúdos de $\mathrm{SiO}_{2}$ entre 73,9 e $76,3 \%$ e teores elevados de $\mathrm{Al}_{2} \mathrm{O}_{3}$, entre 13,8 e $15,1 \%$, similar aqueles observados em associações graníticas peraluminosas (Barbarin 1996).

Apesar dos elevados teores de sílica, a disposição dos elementos maiores nos diagramas de Harker mostra tendências de diferenciação com diminuição dos teores de $\mathrm{TiO}_{2}, \mathrm{MgO}, \mathrm{FeO}_{\mathrm{T}}, \mathrm{Al} 2 \mathrm{O} 3, \mathrm{MnO}, \mathrm{Na}_{2} \mathrm{O}$ e $\mathrm{P}_{2} \mathrm{O}_{5}$ (Fig. 10). Estes padrões de comportamento são compatíveis com rochas comagmáticas afetadas por cristalização fracionada de biotita, plagioclásio, apatita e minerais opacos.
Tabela 3 - Composição representativa dos elementos traços (ppm) de amostras selecionadas dos leucogranitos.

\begin{tabular}{|c|c|c|c|c|c|c|c|}
\hline Amostras & $\begin{array}{l}\text { BR- } \\
20 \mathrm{C}\end{array}$ & BR-22 & $\begin{array}{l}\text { BR- } \\
22 \mathrm{~A}\end{array}$ & $\begin{array}{l}\text { BR- } \\
23 \mathrm{D}\end{array}$ & $\begin{array}{l}\text { BR- } \\
23 \mathrm{G}\end{array}$ & $\begin{array}{l}\text { BR- } \\
21 B\end{array}$ & BR-24 \\
\hline $\mathrm{Be}$ & 19 & 9 & 7 & 13 & 11 & 12 & 9 \\
\hline $\mathrm{Ba}$ & 121 & 26 & 60 & 151 & 654 & 15 & 155 \\
\hline $\mathrm{Sr}$ & 114 & 16 & 21 & 163 & 73 & 17 & 102 \\
\hline $\mathrm{Y}$ & 14 & 14 & 10 & 6 & 8 & 11 & 13 \\
\hline $\mathrm{Zr}$ & 19 & 25 & 34 & 21 & 32 & 21 & 20 \\
\hline $\mathrm{Ga}$ & 25 & 26 & 27 & 24 & 16 & 24 & 27 \\
\hline $\mathrm{Rb}$ & 176 & 288 & 397 & 221 & 162 & 365 & 332 \\
\hline $\mathrm{Nb}$ & 17 & 16 & 18 & 34 & 29 & 20 & 24 \\
\hline $\mathrm{Sn}$ & 2 & 17 & 15 & 2 & 3 & 6 & 26 \\
\hline $\mathrm{La}$ & 4.6 & 5.2 & 6.8 & 1.6 & 4.5 & 4.3 & 5.3 \\
\hline $\mathrm{Ce}$ & 8.2 & 10.9 & 14.1 & 3.5 & 9.2 & 8.9 & 11.1 \\
\hline $\operatorname{Pr}$ & 1.04 & 1.29 & 1.53 & 0.4 & 0.95 & 0.97 & 1.22 \\
\hline $\mathrm{Nd}$ & 5 & 5.4 & 6.2 & 2 & 3.2 & 4.1 & 5.2 \\
\hline $\mathrm{Sm}$ & 1.5 & 1.3 & 1.5 & 0.6 & 0.8 & 1 & 1.4 \\
\hline $\mathrm{Eu}$ & 0.24 & 0.14 & 0.16 & $<0.05$ & 0.32 & 0.1 & 0.17 \\
\hline $\mathrm{Gd}$ & 1.8 & 1.4 & 1.5 & 0.6 & 1 & 1.1 & 1.5 \\
\hline $\mathrm{Tb}$ & 0.4 & 0.3 & 0.3 & 0.1 & 0.2 & 0.3 & 0.4 \\
\hline Dy & 2.5 & 2.2 & 1.8 & 0.9 & 1.5 & 1.8 & 2.2 \\
\hline Ho & 0.4 & 0.4 & 0.3 & 0.2 & 0.3 & 0.4 & 0.4 \\
\hline Er & 1.3 & 1.4 & 0.9 & 0.5 & 0.8 & 1.2 & 1.3 \\
\hline $\mathrm{Tm}$ & 0.23 & 0.3 & 0.16 & 0.1 & 0.15 & 0.25 & 0.24 \\
\hline $\mathrm{Yb}$ & 1.7 & 2.4 & 1.2 & 0.8 & 1.1 & 2.1 & 1.7 \\
\hline $\mathrm{Lu}$ & 0.25 & 0.37 & 0.16 & 0.12 & 0.15 & 0.32 & 0.26 \\
\hline $\mathrm{Ta}$ & 9.8 & 4.5 & 3.3 & 15.6 & 10.5 & 9.3 & 4 \\
\hline Th & 3.7 & 5.3 & 4.1 & 2.5 & 2.6 & 5.4 & 4.8 \\
\hline $\mathrm{U}$ & 9 & 2.8 & 2.8 & 7 & 8 & 8.3 & 3.8 \\
\hline
\end{tabular}



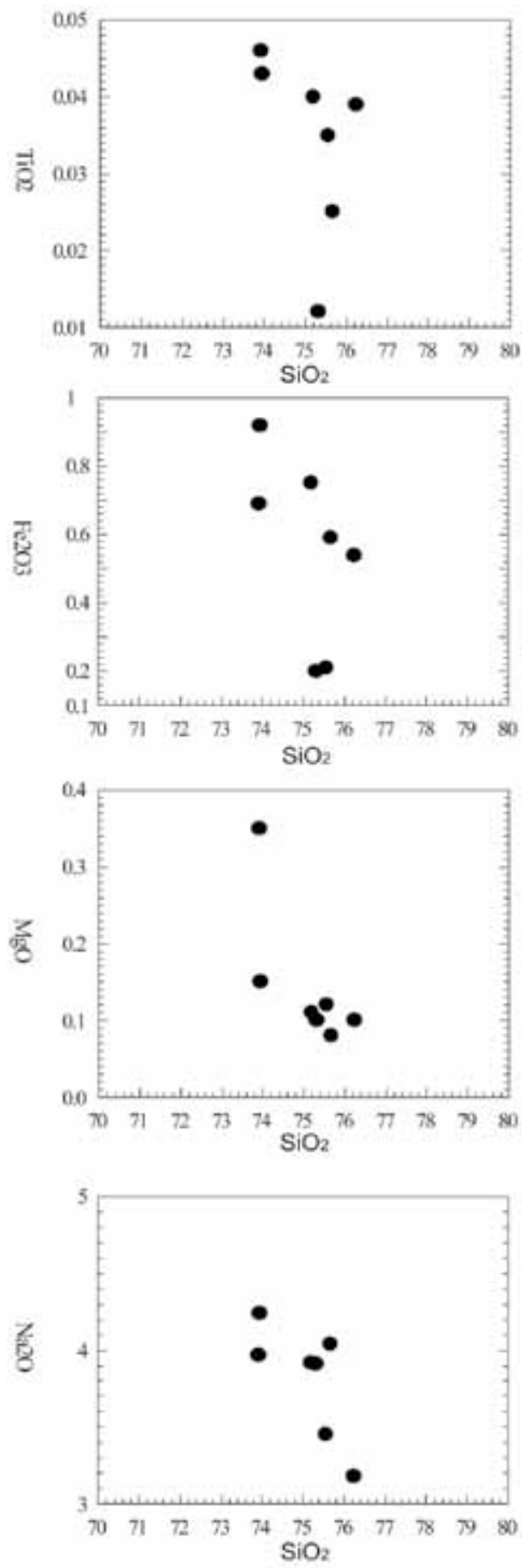
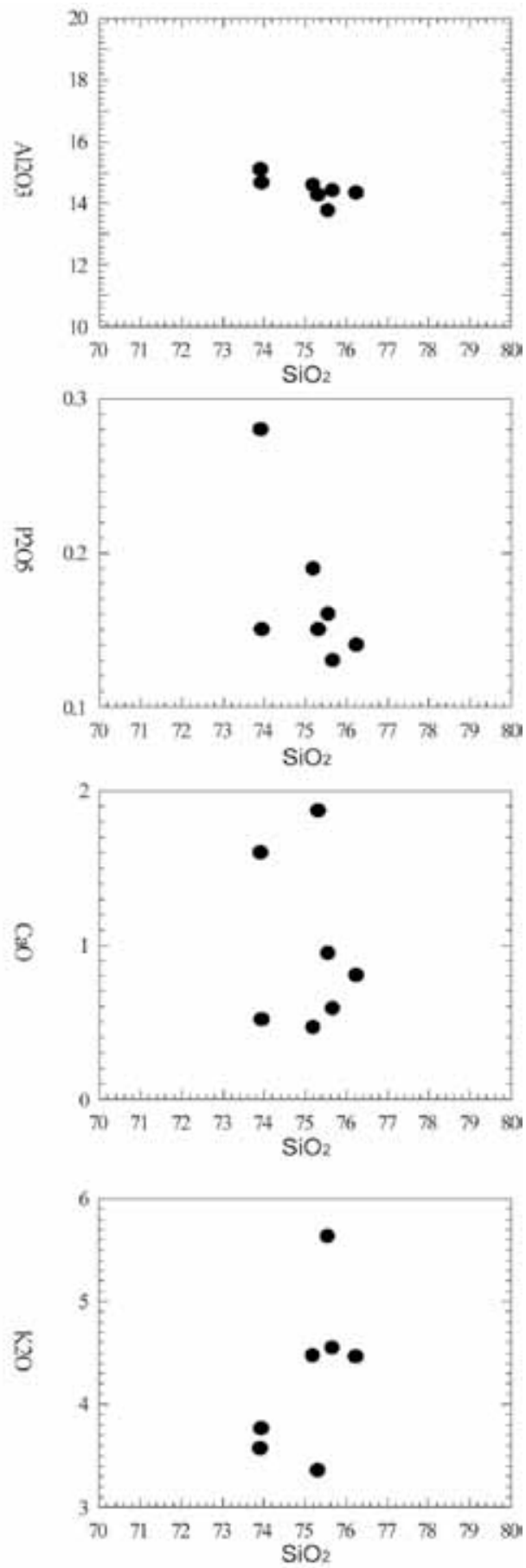

Figura 10 - Diagramas de Harker com variação dos elementos maiores dos granitos estudados.

Os leucogranitos têm caráter subalcalino como ilustrado no diagrama TAS (Middlemost, 1994) e natureza peraluminosa (Figs. 11 e 12). A afinidade cálcico-alcalina destas rochas está indicada pelo diagrama AFM (Irvine and Baragar 1971) (Fig. 13). O teor de $\mathrm{K}_{2} \mathrm{O}$ com relação a $\mathrm{SiO}_{2}$ como proposto por Le Maitre (1989) classifica os leucogranitos como cálcico-alcalinos alto-K (Fig. 14).

Os teores de $\mathrm{Rb}$ e $\mathrm{Sr}$ mostram ampla dispersão nos diagramas composicionais (Fig.15). Esta variação pode estar relacionada com as condições de cristalização, caracterizada por alterações muito variáveis da pressão de voláteis e pela reologia dos magmas em um sistema de alta sílica. Nos leucogranitos afetados pela milonitização pode haver contribuição da atuação de fluidos metamórficos. Os teores e Ba são baixos e mostram uma tendência de aumento incipiente do teor com o aumento do conteúdo de $\mathrm{SiO}_{2}$. Os valores de $\mathrm{Sr}$ (17-163 ppm) e de $\mathrm{Zr}$ são baixos, como esperados para magmas graníticos produzidos pela fusão parcial de rochas crustais em temperaturas relativamente baixas (Wilson 1989; Patiño-Douce \& Johnston 1991; Patiño-Douce 1998, 1999) (Fig. 15). 


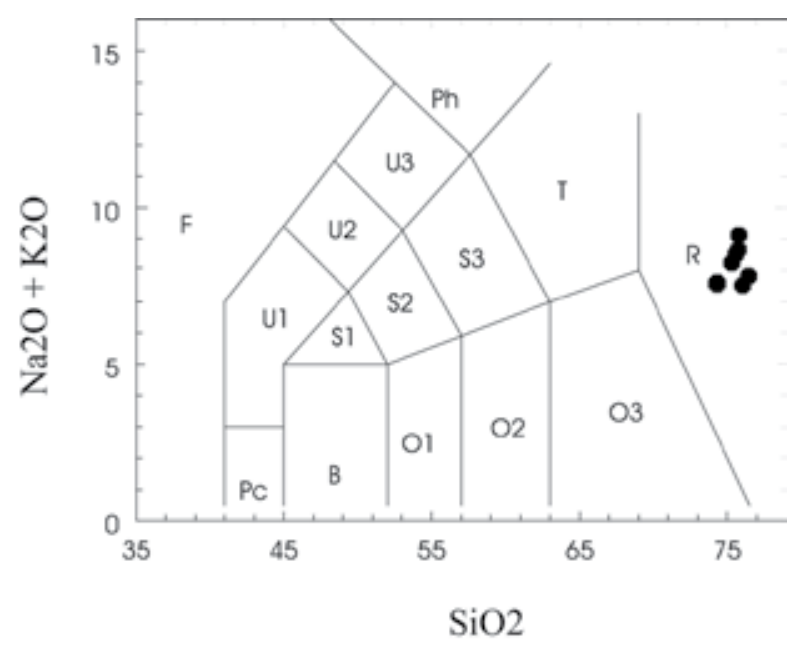

Figura 11 - Diagrama álcalis total versus sílica (TAS) contendo as amostras de leucogranitos da região de Itapema.

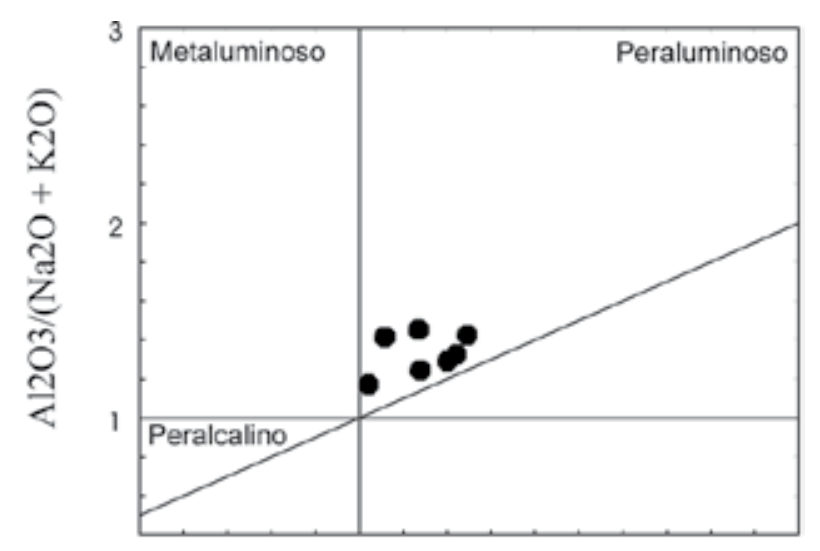

Figura 12 - Diagrama de Shand para avaliação das relações entre álcalis e alumina.

Os padrões de ETR normalizados contra os valores condríticos (Sun 1982) mostram diminuição dos ETR leves em rochas mais diferenciadas (Fig. 16). Os padrões de ETR são homogêneos, sugerindo que as rochas analisadas são co-magmáticas. Os valores de $\mathrm{La}_{\mathrm{N}}$ variam de 7 a 30 e o $\mathrm{Yb}_{\mathrm{N}}$ variam de 5 a 14, com fortes anomalias de Eu e enriquecimento em ETR leves e em ETR pesadas, estas última provavelmente refletindo a presença de granada nos granitos. As amostras 23D e 23G são do maior corpo granítico e mostram valores em geral mais baixos ETR e ausência de anomalia de $\mathrm{Eu}$, refletindo a composição menos diferenciada deste corpo. As fortes anomalias de Eu indicam a abundância de plagioclásio como fase residual. O padrão extremamente fracionado de ETR leves também sugere a presença de granada no restito (Martin 1993).

No diagrama multi-elementar com amostras normalizadas contra os valores condríticos (Sun 1982) os granitos mostram enriquecimento em $\mathrm{U}$, Th e $\mathrm{Rb}$, com anomalias negativas de $\mathrm{Ba}, \mathrm{Sr}$, Eu e Ti, como encontradas em granitos de fusão crustal (Fig. 17). As



Figura 13 - Disposição dos leucogranitos da região de Itapema no diagrama AFM de Irvine \& Baragar (1971).

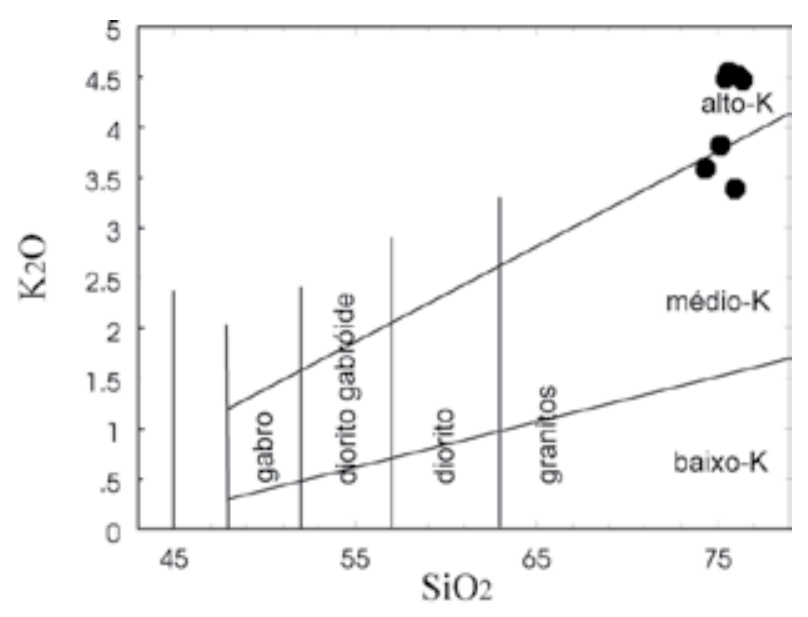

Figura 14 - Diagrama $\mathrm{K}_{2} \mathrm{O}$ com relação a $\mathrm{SiO}_{2}$ (Le Maitre 1989) para classificação das rochas cálcico-alcalinas.

anomalias positivas de ETR leves e pesadas refletem respectivamente, a presença de granada no resíduo da fusão e no granito. A ausência de anomalias de $\mathrm{Nb}$ com relação ao La sugere que os granitos são produtos de fusão crustal. As amostras $23 \mathrm{D}$ e $23 \mathrm{G}$ mostram pequenas diferenças como os teores mais elevados e $\mathrm{Sr}$ e $\mathrm{Ba}$, refletindo mais presença de plagioclásio e talvez uma maior participação dos processos de fusão.

No diagrama $\mathrm{Rb}$ versus $(\mathrm{Y}+\mathrm{Nb})$ (Pearce et al. 1984; Pearce 1996) a maioria das amostras posicionamse no campo dos granitos de fusão crustal relacionados a ambientes colisionais (sin-col) (Fig. 18). As amostras do principal corpo estudado caem no campo dos granitos de arco vulcânico, próximas do limite entre os campos composicionais, podendo refletir a mobilidade do $\mathrm{Rb}$ com relação aos fluidos metamórficos. Os parâmetros para elementos maiores $R_{1}-R_{2}$ (Batchelor \& Bowden 1985) indicam, a mesma similaridade com o 
Granitos peraluminosos intrusivos no Complexo Metamórfico Brusque: registro do magmatismo relacionado a colisão neoproterozóica no Terreno Tijucas, Itapema (SC)


Figura 15 - Diagramas de variação dos elementos traços (ppm) para os leucogranitos utilizando $\mathrm{SiO}_{2}$ como índice de diferenciação.

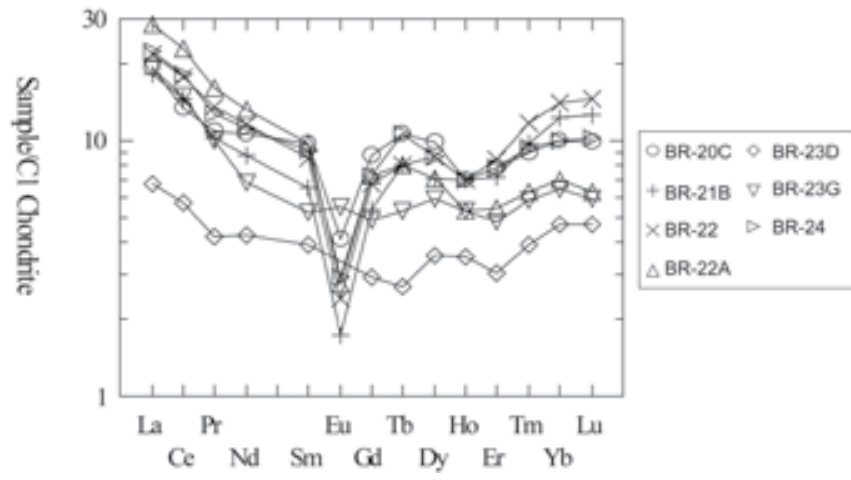

Figura 16 - Abundância dos ETR dos leucogranitos da região de Itapema normalizados pelo condrito (Sun 1982).

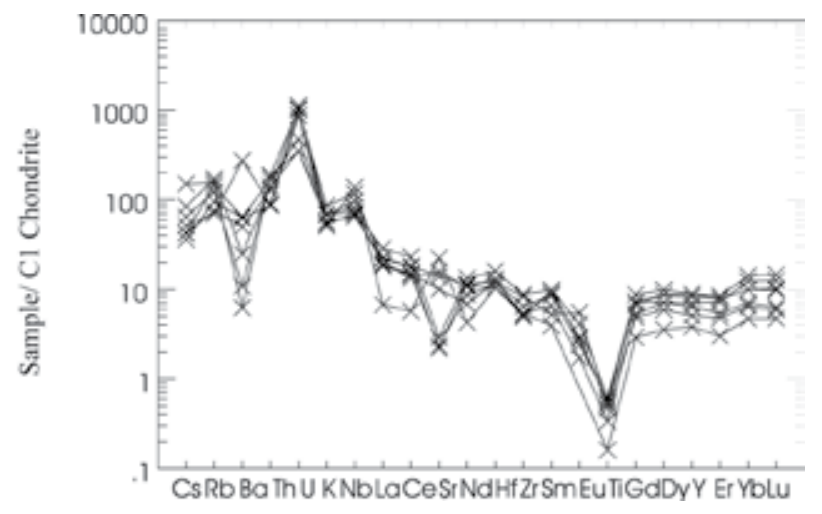

Figura 17 - Diagrama multi-elementar contendo elementos traços normalizados pelo condrito (Sun 1982) para os granitos estudados.

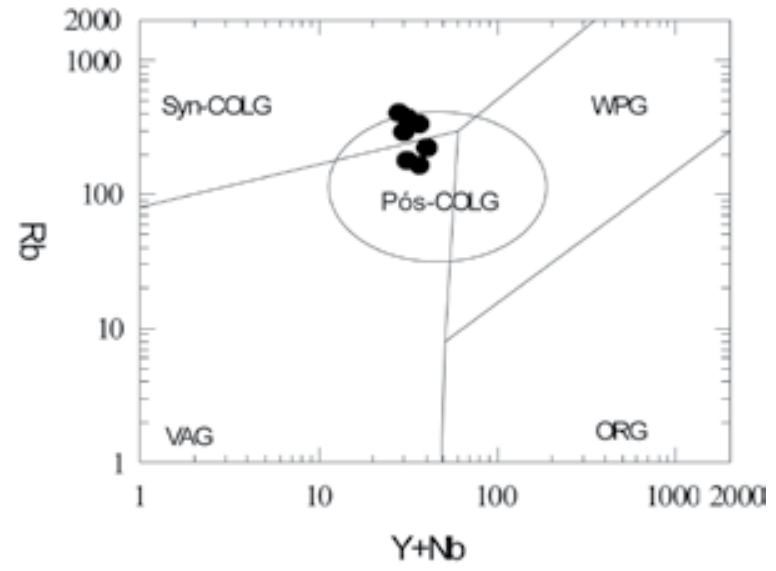

Figura 18 - Disposição dos leucogranitos no diagrama $\mathrm{Rbx} Y+\mathrm{Nb}$ de Pearce et al. (1984) com a subdivisão dos campos dos granitos intra-placa (WPG), arco vulcânico (VAG), sin-colisionais (SYN-COLG), cadeias oceânicas $(O R G)$ e campo circular definido para os granitóides pós-colisionais (Pearce 1996)

magmatismo sin-colisional (Fig. 19).

CONSIDERAÇÕES FINAIS Patiño-Douce \& McCarthy (1998a) admitem que a fusão parcial de metapelitos, metagrauvacas e/ou tonalitos podem produzir leucogranitos em segmentos crustais espessados por sistemas colisionais. Com o aporte de fluidos aquosos a fusão de metapelitos (muscovita xistos) e metagrauvacas 


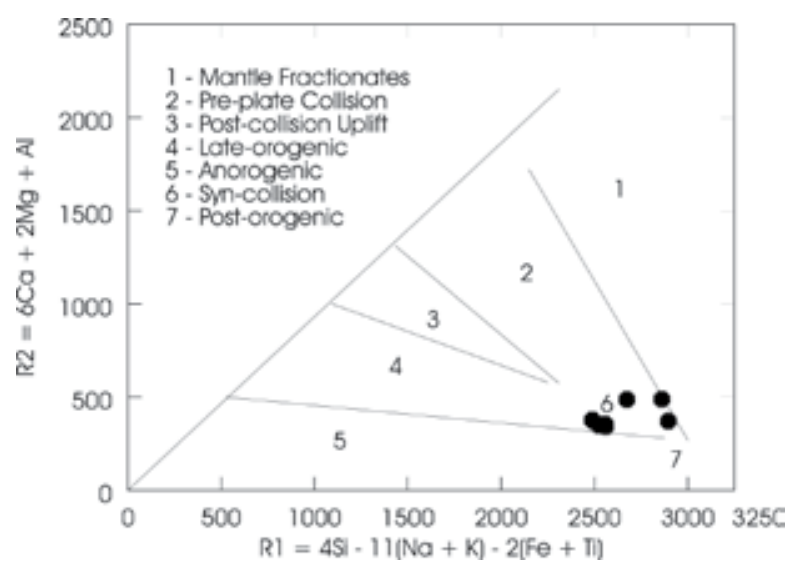

Figura 19 - Disposição dos leucogranitos no diagrama $R_{1}-R_{2}$ (Batchelor \& Bowden 1985).

em temperaturas entre 700 e $800^{\circ} \mathrm{C}$ e níveis intermediários de profundidade gera fusões de composições trondhjemíticas e resíduos ricos em micas. Entretanto, estas condições são atingidas somente quando seqüências de sedimentos frios e hidratados são soterradas muito rapidamente. Normalmente o aumento da pressão e da temperatura em cinturões colisionais ocorre de modo lento e gradual. Desta forma, a fusão parcial está associada com processos de fusão por desidratação (dehydration melting), onde $\mathrm{a}_{2} \mathrm{O}$ necessária para ocasionar a fusão é providenciada pela quebra incongruente de minerais hidratados (Thompson \& Algnor 1977; Thompson 1982; Clemens \& Vielzeuf 1987; Clemens \& Droop 1998).

A ocorrência de fusão por desidratação nestas condições afeta somente xistos ricos em muscovita, gerando leucogranitos peraluminosos e resíduos de composição granulítica ricos em granada, plagioclásio e K-feldspato. Nestas condições a fusão parcial de tonalitos é restrita e gera magmas pobres em $\mathrm{Al}$, formando os granitos do tipo A. Para gerar líquidos graníticos peraluminosos a fusão de tonalitos e metagrauvacas só poderá ocorrer em condições de temperaturas e pressões mais elevadas $\left(>900^{\circ} \mathrm{C}\right.$ e $>1 \mathrm{GPa}$ para líquidos potássicos e entre 1,2 e 2,0 GPa para líquidos sódicos). Estas condições são verificadas somente em orógenos colisionais que sofreram descolamento do manto litosférico, que é um processo comum no período posterior ao pico da colisão (slab-breakoff) como descrito por Davies \& Von Blanckenburg (1998).

Variações na razão $\mathrm{K}_{2} \mathrm{O} / \mathrm{Na}_{2} \mathrm{O}$ das fusões são relacionadas a composição dos protólitos, extensão da fusão, atividade de $\mathrm{H}_{2} \mathrm{O}$ e a pressão, sendo relacionadas ao comportamento das micas e do plagioclásio durante as reações de fusão (Patiño Douce 1996; Patiño Douce \& Harris 1998b). As fusões geradas em baixas pressões tendem a ser ricas em $\mathrm{K}_{2} \mathrm{O}$ com relação ao $\mathrm{Na}_{2} \mathrm{O}$ independente da composição do protólito. Quando a pressão aumenta, a quebra incongruente do plagioclásio libera o componente albítico que passa a fazer parte da fusão.

Nas porções profundas dos cinturões colisio- nais as assembléias residuais formadas durante a anatexia gradam para as associações da fácies granulito ou eclogito. Na região estudada o Complexo Metamórfico Brusque está disposto entre outras unidades metamórficas como o Complexo Camboriú e o Complexo Granulítico de Santa Catarina. Estas unidades foram afetadas por processos metamórficos sob condições da fácies Anfibolito Superior e Granulito, de idade Neoproterozóica e relacionado ao final do Ciclo Brasiliano (Hartmann et al. 2000; Ticky et al. 2004; Philipp et al. 2009). Durante este evento metamórfico as unidades do embasamento poderiam fundir e gerar os leucogranitos estudados. No Complexo Camboriú a migmatização dos gnaisses pelíticos apresenta materiais residuais contendo granada, plagioclásio, biotita, K-feldspato e silimanita (Philipp et al. 2001b).

A avaliação dos tipos de protólitos que geram o magmatismo peraluminoso pode ser feita com base na composição litogeoquímica dos granitos. Com base em ampla revisão de dados experimentais disponíveis e relativos a fusão por desidratação de diversos materiais crustais, Jung \& Pfänder (2007) propõem a identificação dos materiais fontes a partir da composição dos elementos maiores de granitos peraluminosos. Os estudos são baseados no cruzamento das razões $\mathrm{CaO} / \mathrm{Na}_{2} \mathrm{O}$ e $\mathrm{Al}_{2} \mathrm{O}_{3} / \mathrm{TiO}_{2}$ obtidas a partir da fusão de metapelitos, metarenitos, tonalitos e anfibolitos-eclogitos. As baixas razões de $\mathrm{CaO} / \mathrm{Na}_{2} \mathrm{O}$, entre 0,11 e 0,47 , associadas aos elevados valores obtidos para a razão $\mathrm{Al}_{2} \mathrm{O}_{3} / \mathrm{TiO}_{2}$, entre 320 e 570, indicam que os leucogranitos do Complexo Brusque foram originados provavelmente pela fusão de rochas pelíticas. Os teores relativamente elevados de quartzo e feldspatos encontrados nos termos pelíticos deste complexo podem ser responsáveis pela ausência de líquidos muito aluminosos contendo alumino-silicatos, como encontrado comumente em granitos gerados pela fusão de metapelitos.

Estes mesmos autores comprovaram matematicamente a correlação existente entre as temperaturas de fusão parcial dos diversos tipos de protólitos e os valores da razão $\mathrm{Al}_{2} \mathrm{O}_{3} / \mathrm{TiO}_{2}$. A partir desta sistemática Jung \& Pfänder (2007) demonstraram a utilização desta razão como um parâmetro para estimar a temperatura de geração das fusões graníticas de natureza peraluminosa. Os cálculos realizados a partir da composição dos leucogranitos intrusivos no Complexo Brusque permitem estabelecer o intervalo entre 696 e $713^{\circ} \mathrm{C}$ como as temperaturas prováveis de formação dos líquidos geradores dos granitos estudados (Tab. 4). Os levantamentos realizados a partir do uso de parâmetros de cálculos por diferentes funções matemáticas (integração, equação exponencial e regressão linear) confirmam os protólitos pelíticos como prováveis materiais fontes para a formação dos granitos que cortam o complexo.

Os dados geoquímicos dos leucogranitos mostram uma composição peraluminosa com teores relativamente elevados de $\mathrm{Na}_{2} \mathrm{O}$, resultando em razões $\mathrm{K}_{2} \mathrm{O} / \mathrm{Na}_{2} \mathrm{O}$ baixas, comumente em torno de 1 . As restrições composicionais como a baixa razão $\mathrm{CaO} / \mathrm{Na}_{2} \mathrm{O}$ e as relações petrológicas e tectônicas com o Complexo Metamórfico Brus- 
Tabela 4 - Temperaturas de fusão de protólitos pelíticos e quartzo-feldspáticos calculadas pelo termômetro $\mathrm{Al}_{2} \mathrm{O}_{3}$ TiO $\mathrm{Ti}_{2}$ (Jung \& Pfander 2007) com base na composição química dos leucogranitos da região de Itapema.

\begin{tabular}{c|c|c|c|c|c|c|c}
\hline Amostras & $\begin{array}{c}\text { BR- } \\
20 \mathrm{C}\end{array}$ & $\begin{array}{c}\text { BR- } \\
22\end{array}$ & $\begin{array}{c}\text { BR- } \\
22 \mathrm{~A}\end{array}$ & $\begin{array}{c}\text { BR- } \\
23 \mathrm{D}\end{array}$ & $\begin{array}{c}\text { BR- } \\
23 \mathrm{G}\end{array}$ & $\begin{array}{c}\text { BR- } \\
21 \mathrm{~B}\end{array}$ & $\begin{array}{c}\text { BR- } \\
24\end{array}$ \\
\hline $\mathrm{CaO} / \mathrm{Na}_{2} \mathrm{O}(\%)$ & 0.40 & 0.12 & 0.11 & 0.47 & 0.27 & 0.14 & 0.25 \\
\hline $\mathrm{Al}_{2} \mathrm{O}_{3} / \mathrm{TiO}_{2}(\%)$ & 328.3 & 340.7 & 364.5 & 1187 & 393.7 & 576 & 367.6 \\
\hline $\begin{array}{c}\text { Power Law } \\
\text { (pelites) }\end{array}$ & 713.9 & 710.3 & 703.7 & 598.5 & 696.3 & 660.9 & 702.89 \\
\hline $\begin{array}{c}\text { Power Law } \\
\text { (qz-feldsp.) }\end{array}$ & 608.20 & 604.37 & 597.43 & 488.3 & 589.62 & 552.51 & 596.49 \\
\hline $\begin{array}{c}\text { Exponencial } \\
\text { Law (p) }\end{array}$ & 694.71 & 690.16 & 681.85 & 533.92 & 672.37 & 625.57 & 680.81 \\
\hline $\begin{array}{c}\text { Exponencial } \\
\text { Law (qz-f.) }\end{array}$ & 585.2 & 580.10 & 570.84 & 408.89 & 560.28 & 508.1 & 569.69 \\
\hline $\begin{array}{c}\text { Linear } \\
\text { Regression (p) }\end{array}$ & 575.74 & 566 & 548.16 & 262.44 & 527.76 & 482.26 & 546 \\
\hline $\begin{array}{c}\text { Linear } \\
\text { Regression } \\
\text { (qz-f.) }\end{array}$ & 530.62 & 521.6 & 505.1 & 241.32 & 486.23 & 394.28 & 503.03 \\
\hline
\end{tabular}

Símbolos: $\mathrm{p}$ = protólito pelítico, qz-f = protólito quartzo-feldspático.

que, também sugerem que o magmatismo leucogranítico seria gerado por fusões de protólitos metassedimentares.

CONCLUSÕES Os leucogranitos estudados constituem corpos tabulares posicionados nas superfícies axiais das dobras $F_{2}$, relacionadas a segunda fase de metamorfismo e deformação regional do CMB. A concordância entre a foliação magmática e a milonítica nestes corpos confirma o caráter sin- $\mathrm{D}_{2}$ desta granitogênese e vincula os mesmos ao pico do metamorfismo colisional que afetou este complexo e formou a xistosidade $\mathrm{S}_{2}$. A vinculação da formação dos granitóides a principal fase da tectônica deformadora do Complexo Metamórfico Brusque sugere que este magmatismo é de idade Neoproterozóica. As relações estruturais e a ausência de metamorfismo de contato diferenciam estes corpos dos granitos Valsungana, Guabiruba e Serra dos Macacos.

Os parâmetros composicionais são consis- tentes com uma evolução associada com magmas gerados a partir da fusão parcial de rochas crustais de composição pelítica, com participação restrita de processos de diferenciação, provavelmente de cristalização fracionada. Estes padrões são muito similares aos descritos em granitos peraluminosos Fanerozóicos por Watson \& Harrison (1983), Pearce et al. (1984), Patiño-Douce (1999), Barbarin (1996), entre outros. As feições composicionais identificadas nos leucogranitos são descritas em rochas formadas por fusão parcial de rochas pelíticas sobre pressões intermediárias, deixando um resíduo de composição granulítica (Patino-Douce \& McCarthy 1998a; Patiño-Douce 1999). A afinidade cálcico-alcalina alto-K, bem como, a elevada razão ETR leves/ $\mathrm{Nb}$, e os padrões dispostos nos diagramas de Pearce et al. (1984) e Pearce (1996) são consistentes com um magmatismo gerado em um cinturão orogênico colisional.

Apesar das feições composicionais indicarem uma origem a partir da fusão parcial de rochas metassedimentares, não foi identificado nas litologias do Complexo Brusque condições metamórficas compatíveis com as necessárias para a fusão in situ. Esta limitação sugere que os leucogranitos estudados são alóctones e provavelmente derivam de porções mais profundas da crosta.

As relações estruturais entre o posicionamento dos corpos graníticos e a evolução metamórfico-deformacional do $\mathrm{CMB}$, associada aos parâmetros geoquímicos e as feições tectônicas e geocronológicas são consistentes com um magmatismo relacionado a fusão crustal em ambiente colisional no final do Ciclo Brasiliano, sob condições metamórficas mínimas da fácies anfibolito superior, no intervalo entre 690 e $720^{\circ} \mathrm{C}$.

Apesar dos poucos dados geocronológicos, a formação do cinturão metamórfico provavelmente ocorreu no fim do Neoproterozóico, marcando a amalgamação entre uma sequência de sedimentos de margem passiva situada nos limites de uma microplaca continental representada pelo Complexo Granulítico de Santa Catarina, no lado brasileiro, contra o Cráton do Kalahari, na porção sul da África.

Agradecimentos Os autores agradecem ao $\mathrm{CNPq}$ (processo $\mathrm{N}^{\circ} 473847 / 2006-0$ ) pelo suporte financeiro que permitiu a realização dos trabalhos de campo e laboratório, pela concessão de bolsa de doutorado (Roberto Sacks de Campos) e de produtividade (processo №301915/2006-7, de Ruy Paulo Philipp) e e a CAPES (processo $\mathrm{N}^{\circ}$ 0561/07-0) pela concessão de bolsa de pós-doutoramento no exterior. Os autores agradecem aos revisores anônimos da RBG pela revisão, discussão e importantes sugestões ao texto final.

\section{Referências}

Barbarin B. 1996. Genesis of the two main types of peraluminous granitoids, Geology, 24(4):295-298.

Barbarin B. 1997. From the mineralogical composition of granitoids to their origins and tectonic settings. In: SBG,
International Symposium on Granites and Associated Mineralizations, 2, Salvador, Bahia, SBG, p. 95-97.

Basei M.A.S. 1985. O Cinturão Dom Feliciano em Santa Catarina. Tese de Doutoramento, Instituto de Geociên- 
cias, Universidade de São Paulo, 190 p.

Basei M.A.S. \& Teixeira W. 1987. Geocronologia do PréCambriano/Eopaleozóico de Santa Catarina, In: Silva L.C \& Bortoluzzi C.A. (eds.) Texto explicativo para o mapa geológico de estado de Santa Catarina - 1:500.000. Florianópolis, DNPM/CPRM, p.91-130.

Basei M.A.S., Grasso C.B., Vlach S.R.F., Nutman A., Siga Jr. O., Osako L.S. 2008. "A"-Type Rift-related granite and the Lower Cryogenian age for the beginning of the Brusque Belt Basin, Dom Feliciano Belt, Southern Brazil. In: South American Symposium on Isotope Geology, 6, San Carlos de Bariloche, p.1-5.

Basei M.A.S. 1990. O Grupo Brusque: uma evolução monocíclica. In: SBG, Congresso Brasileiro de Geologia, 36, Natal, Anais, 6:2649-2657.

Batchelor R.A. \& Bowden P. 1985. Petrogenetic interpretation of granitoid rocks series using multicationic parameters. Chemical Geology, 48:43-55.

Bitencourt M.F. \& Nardi L.S.V. 2004. The role of xenoliths and flow segregation in the genesis and evolution of Paleoproterozoic Itapema Granite, a crustally-derived magma of shoshonitic affinity from southern Brazil, $L i$ thos, 73(1):1-19.

Caldasso A.L., Krebs A.S.J., Silva M.A.S., Camozzato E., Ramgrab G.E. 1995. Mapa Geológico 1:50.000 da Folha Brusque, SC, SG-22-Z-D-II-1, Programa de Levantamentos Geológicos Básicos, Brasília, CPRM, 243 p.

Campos R.S. 2007. Petrografia e geoquímica das rochas metavulcânicas máficas e ultramáficas do Complexo Metamórfico Brusque, região da Serra da Miséria, Itapema, $S C$. Dissertação de Mestrado, Instituto de Geociências, Universidade Federal do Rio Grande do Sul, 83 p.

Campos R.S. \& Philipp R.P. 2007. Petrografia e geoquímica das rochas metavulcânicas máficas e ultramáficas do Complexo Metamórfico Brusque, região da Serra da Miséria, Itapema, SC, Revista Brasileira de Geociências, 37(4):705-726.

Clemens J.D. \& Vielzeuf D. 1987. Constrains on melting and magma production in the crust. Earth and Planetary Science Letters, 86:287-306.

Clemens J.D. \& Droop G.T.R. 1998. Fluids, P-T paths and the fates of anatectic melts in the Earth's crust. Lithos, 44:21-36.

Davies J.H. \& Von Blanckenburg F. 1998. Thermal controls on slab breakoff and the rise of high-pressure rocks during continental collisions. In: Hacker B.R. \& Liou J.G. (eds.) When the continents collide: geodynamics and geochemistry of Ultra-High Pressure rocks. Netherlands, Kluwer Academic Publishers, p.97-115.

Hartmann L.A., Leite J.A.D., Silva L.C., Remus M.V.D., McNaughton N.J., Groves D.I., Fletcher I.R., Santos J.O.S., Vasconcellos M.A.Z. 2000. Advances in SHRIMP geochronology and their impact on understanding the tectonic and metallogenic evolution of southern Brazil. Australian Journal of Earth Sciences, 47:829-844.

Hartmann L.A., Bitencourt M.F, Santos J.O.S., McNaughton N.J., Rivera C.B., Betiollo L. 2003. Prolonged Paleoproterozoic magmatic participation in the Neoproterozoic Dom Feliciano Belt, Santa Catarina, Brazil, based on zircon U-Pb SHRIMP geochronology. Journal of South
American Earth Sciences, 16:477-492.

Hartmann L.A., Chemale Jr. F., Philipp R.P. 2007. Evolução geotectônica do Rio Grande do Sul no Precambriano. In: Ianuzzi R. \& Frantz J.C. (eds.) 50 Anos de Geologia. Instituto de Geociências. Contribuições, Porto Alegre, Ed. Comunicação e Identidade-CIGO-IG-UFRGS, 4:97123.

Jung S. \& Pfänder J.A. 2007. Source composition and melting temperatures of orogenic granitoids: constrains from $\mathrm{CaO} / \mathrm{Na}_{2} \mathrm{O}, \mathrm{Al}_{2} \mathrm{O}_{3} / \mathrm{TiO}_{2}$ and accessory mineral saturation thermometry, European Journal of Mineralogy, 19:859870.

Irvine T.N. \& Baragar W.R.A. 1971. A guide to the chemical classification of the common volcanic rocks. Canadian Journal of Earth Sciences, 8:523-548.

Le Maitre R.W. 1989. A classification of igneous rocks and glossary of terms. Oxford, Blackwell, $193 \mathrm{p}$.

Liégeois J.P. 1998. Some words on the post-collisional magmatism. Lithos, 45:xv-xvii.

Liégeois J.P., Navez J., Hertogen J., Black R. 1998. Contrasting origin of post-collisional high-K calc-alkaline and shoshonitic versus alkaline and peralkaline granitoids. The use of sliding normalization. Lithos, 45:1-28.

Martin H. 1993. The mechanisms of petrogenesis of the Archean continental crust - comparison with modern processes. Lithos, 30:373-388.

Middlemost E. 1994. Naming materials in the magma/igneous rock system. Earth-Science Rewiews, 37:215-224.

Patiño Douce A.E. \& Johnston A.D. 1991. Phase equilibria and melt productivity in the pelitic system: implications for the the origin of peraluminous granitoids and aluminous granulites. Contributions to Mineralogy and Petrology, 107:202-218.

Patiño Douce A.E. 1996. Effects of pressure and $\mathrm{H}_{2} \mathrm{O}$ contents on the compositions of primary crustal melts. Transactions of the Royal Society of Edinburg: Earth Sciences, 87:623-639.

Patiño Douce A.E. 1999. What do experiments tell us about the relative contributions of crust and mantle to the origin of granitic magmas? In: Castro A., Fernandez C., Vigneresse J.E. (eds.) Undestanding granites: New and Classical Techniques. Geological Society of London, Special Publications, 168:55-75.

Patiño Douce A.E. \& Mc Carthy T.C. 1998. Melting of crustal rocks during continental collision and subduction. In: Hacker B.R. \& Liou J.G. (eds.) When the continents collide: geodynamics and geochemistry of Ultra-High Pressure rocks. Netherlands, Kluwer Academic Publishers, p.27-55.

Pearce J.A. \& Cann J.R. 1973. Tectonic setting of basic volcanic rocks determined using trace eIement analyses. Earth Planet. Sci. Lett., 19:290-300.

Pearce T.H., Gorman B.E., Birkett T.E. 1975. The $\mathrm{TiO}_{2}-\mathrm{K}_{2} \mathrm{O}-$ $\mathrm{P}_{2} \mathrm{O}_{5}$ diagram: a method of discriminating between oceanic and non-oceanic basalts. Earth Planet. Sci. Lett., 24:419-426.

Pearce J.A., Harris N.B.W., Tindle A.G. 1984. Trace element discrimination diagrams for the tectonic interpretation of granitic rocks. J. Petrology, 25:956-983.

Pearce J.A. 1996. Sources and settings of granitic rocks. Epi- 
sodes, 19(4):120-125.

Pereira R.M., Ávila C.A., Neumann R., Mendes J.C., Moura C.A. 2005. Rare metal oxide mineralization related to two neoproterozoic tourmaline granites from the interference zone of the Ribeira and Brasília belts, Minas Gerais, Brazil. Revista Brasileira de Geociências, 35:341-350.

Philipp R.P., Mallmann G., Prado M., Silva M.M.A., Souza E.R., Souza M.M.A., Wild F., Arend S., Liz J.D., Duarte L.C., Oliveira A.S. 2001a. Caracterização litológica e condições metamórficas do Complexo Metamórfico Brusque na região de Camboriú-Tijucas, SC. In: SBG, Simpósio Nacional de Estudos Tectônicos, 8, International Symposium on Tectonics of Brazilian Geological Society, 2, Recife, Boletim de Resumos Expandidos, p.93-97.

Philipp R.P., Wild F., Duarte L.C., Oliveira A.S., Arend S., Rivera C.B., Samberg E., Morales L.F.G., Mallmann G. 2001b. Caracterização litológica, estrutural e condições metamórficas do Complexo Camboriú, Itapema, SC. In: SBG, Simpósio Nacional de Estudos Tectônicos, 8, International Symposium on Tectonics of Brazilian Geological Society, 2, Recife, Boletim de Resumos Expandidos, p.103-105.

Philipp R.P., Mallmann G., Bitencourt M.F., Oliveira A.S., Souza E.R. 2001c. Feições estruturais e evolução metamórfica da porção leste do Complexo Metamórfico Brusque, sul do Brasil. In: Congresso Latino-Americano, 11, Congresso Uruguaio de Geologia, 3, Montevidéo, Boletim de Resumos Expandidos, 1:7-11.

Philipp R.P., Mallmann G., Bitencourt M.F., Souza E.R., Liz J.D., Wild F., Arend S., Oliveira A.S., Duarte L.C., Rivera C.B., Prado M. 2004. Caracterização Litológica e Evolução Metamórfica da Porção Leste do Complexo Metamórfico Brusque, Santa Catarina. Revista Brasileira de Geociências, 34(1):21-34.

Sander A. 1992. Petrologia e Litoquímica de uma parcela da Seqüencia Vulcano-Sedimentar do Complexo Metamórfico Brusque na região do Ribeirão do Ouro, SC. Dissertação de Mestrado, Instituto de Geociências, Universidade Federal do Rio Grande do Sul, 167 p.

Silva L.C. \& Dias A.A. 1981. Projeto Timbó-Barra Velha, SC, Brasil. Porto Alegre, DNPM- CPRM, 282 p.

Silva L.C. 1991. O Cinturão Metavulcanossedimentar Brus- que e a evolução policíclica das faixas dobradas Proterozóicas no sul do Brasil: uma revisão. Revista Brasileira de Geociências, 21(1):60-73.

Silva L.C., McNaughton N.J., Santos J.O.S. 2002. Datações $\mathrm{U}-\mathrm{Pb} \mathrm{SHRIMP}$ do vulcanismo félsico na Bacia Brusque, Orógeno Pelotas, SC. In: SBG, Congresso Brasileiro de Geologia, 41, João Pessoa, Anais, p.510.

Stevens G., Clemens J.D., Droop G.T.R. 1997. Melt production during granulite-facies anatexis: experimental data from "primitive" metasedimentary protoliths. Contribuition to Mineralogy Petrology, 128:352-370.

Streckeisen A.L. 1976. To each plutonic rock its proper name. Earth Science Review, 12:1-33.

Sun S.S. 1982. Chemical composition and origin of the Earth's primitive mantle. Geochemical et Cosmochemical Acta, 46:179-192.

Tickyj H., Hartmann L.A., Vasconcellos M.A.Z., Philipp R.P., Remus M.V.D. 2004. Electron-microprobe dating of monazite substantiates ages of major geological events in the southern Brazilian Shield. Journal of South American Earth Sciences, Amsterdam, 16(8):699-713.

Thompson A.B. 1982. Dehydration melting of pelitic rocks and the generation of $\mathrm{H}_{2} \mathrm{O}$ undersaturated granitic liquids. American Journal of Science, 282:1567-1595.

Thompson A.B. \& Algnor J.R. 1977. Model system for anatexis of pelitic rocks. I. Theory of melting reactions in the system $\mathrm{KAlO}_{2}-\mathrm{NaAlO}_{2}-\mathrm{Al}_{2} \mathrm{O}_{3}-\mathrm{SiO}_{2}-\mathrm{H}_{2} \mathrm{O}$. Contributions to Mineralogy and Petrology, 63:247-269.

Watson E.B. \& Harrison M.T. 1983. Zircon saturation revisited: temperature and composition effects in a variety of crustal magma types. Earth Planet.Sci.Letters, 64:295304.

Wilson M. 1989. Igneous Petrology. London, Unwin and Hyman, 466 p.

Winkler H.G.F. 1983. A survey of granitic rocks of the Damara Orogen and considerations of their origin. In: Martin H. \& Eder P.W. (eds.) Intracontinental fold belts. Berlin, Springer-Verlag, p.817-837.

White A.J.R. \& Chappell B.W. 1977. Ultrametamorphism and granitoid genesis. Tectonophysics, 43:7-22.

Manuscrito ID 12152 Submetido em 05 de setembro de 2008 Aceito em 17 de março de 2010 